\title{
EFEITO DA IRRADIAÇÃO GAMA NA COMPOSIÇÃO QUÍMICA DA DENTINA RADICULAR
}

RIBEIRÃO PRETO 



\title{
LÍVIA BUENO CAMPI
}

\section{EFEITO DA IRRADIAÇÃO GAMA NA COMPOSIÇÃO QUÍMICA DA DENTINA RADICULAR}

\begin{abstract}
Dissertação de Mestrado apresentada à Faculdade de Odontologia de Ribeirão Preto da Universidade de São Paulo para a obtenção do grau de Mestre em Ciências - Programa: Odontologia Restauradora - Área de concentração: Odontologia Restauradora (Opção: Endodontia).
\end{abstract}

Orientador: Prof. Dr. Paulo César Saquy

RIBEIRÃO PRETO 
AUTORIZO A REPRODUÇÃO E DIVULGAÇÃO TOTAL OU PARCIAL DESTE TRABALHO, POR QUALQUER MEIO CONVENCIONAL OU ELETRÔNICO, PARA FINS DE ESTUDO E PESQUISA, DESDE QUE CITADA A FONTE.

Assinatura do autor:

Data: / 2017

FICHA CATALOGRÁFICA

Campi, Lívia Bueno

Efeito da irradiação gama na composição química da dentina radicular. Ribeirão Preto, 2017.

95p.: il.; $30 \mathrm{~cm}$

Dissertação de mestrado, apresentada na Faculdade de Odontologia de Ribeirão Preto da Universidade de São Paulo (FORP-USP), área de concentração: Odontologia Restauradora - Endodontia.

Orientador: Prof. Dr. Paulo César Saquy

1. Espectroscopia Raman Confocal 2. Radioterapia. 3. Dentina. 
CAMPI, LB. Efeito da irradiação gama na composição química da dentina radicular.

Dissertação de Mestrado apresentada à Faculdade de Odontologia de Ribeirão Preto da Universidade de São Paulo para a obtenção do grau de Mestre em Ciências Programa: Odontologia Restauradora Área de concentração: Odontologia Restauradora (Opção: Endodontia).

Aprovado em:

\section{Banca Examinadora}

Prof. Dr. Paulo César Saquy (Orientador) Instituição: Faculdade de Odontologia de Ribeirão Preto/USP

Julgamento: Assinatura:

Prof(a). Dr(a).: Instituição

Julgamento: Assinatura:

Prof(a). $\operatorname{Dr}(\mathrm{a})$. : Instituição Julgamento: Assinatura:

Prof(a). Dr(a).: Instituição Julgamento: Assinatura: 


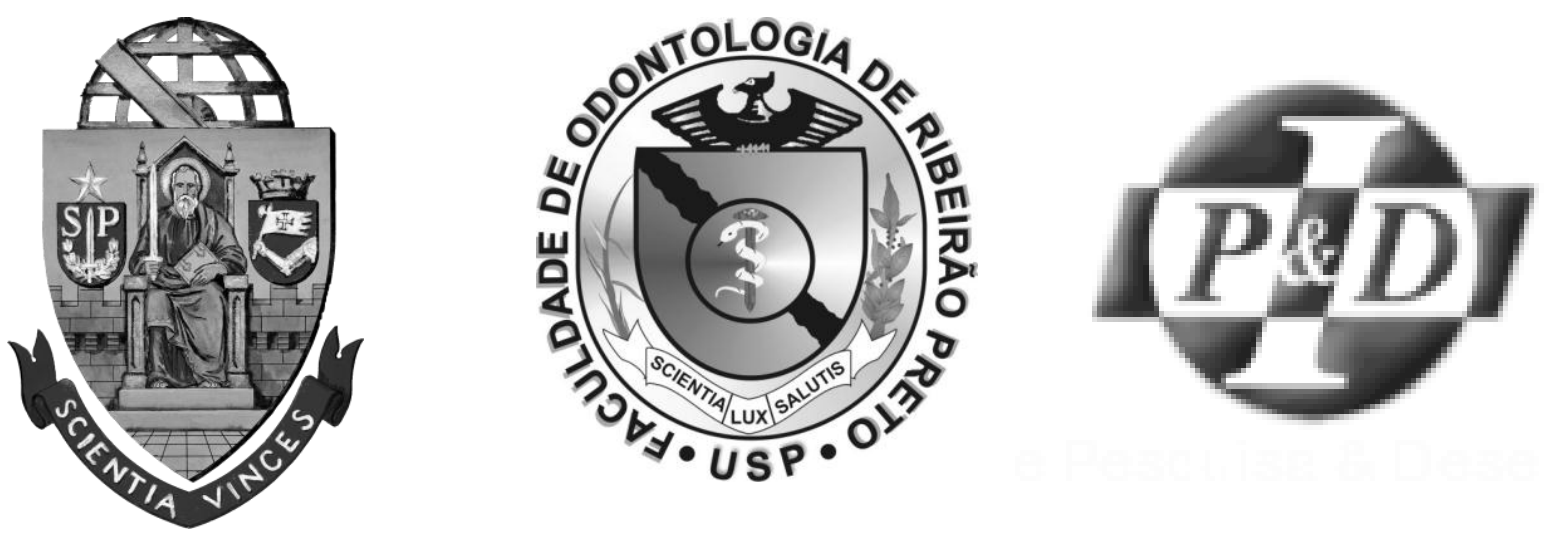

Este trabalho de pesquisa foi realizado nas seguintes instituições: Laboratório de Pesquisa em Endodontia do Departamento de Odontologia Restauradora da Faculdade de Odontologia de Ribeirão Preto da Universidade de São Paulo e no Instituto de Pesquisa e Desenvolvimento da Universidade do Vale do Paraíba. Apoio CAPES. 



\section{Dedicatóría}

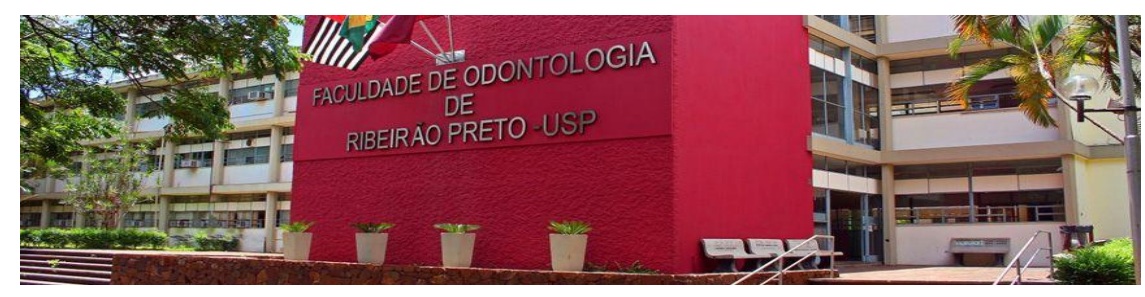



A Deus, pelas oportunidades concedidas, por me guiar e dar forças para superar todos os obstáculos da vida!

Aos meus pais, José Carlos Campi e Rosângela Bueno Campi, meus grandes exemplos, por serem a base de todo meu conhecimento, confiarem em minha capacidade, me apoiando e incentivando. Pelo amor, carinho, amizade, companheirismo e cumplicidade. Sou eternamente grata a vocês.

Aos meus irmãos, Letícia Bueno Campi e Eduardo Bueno Campi, pelo amor, companheirismo, amizade e por estarem presentes em todos momentos importantes da minha vida.

Amo muito vocês! 


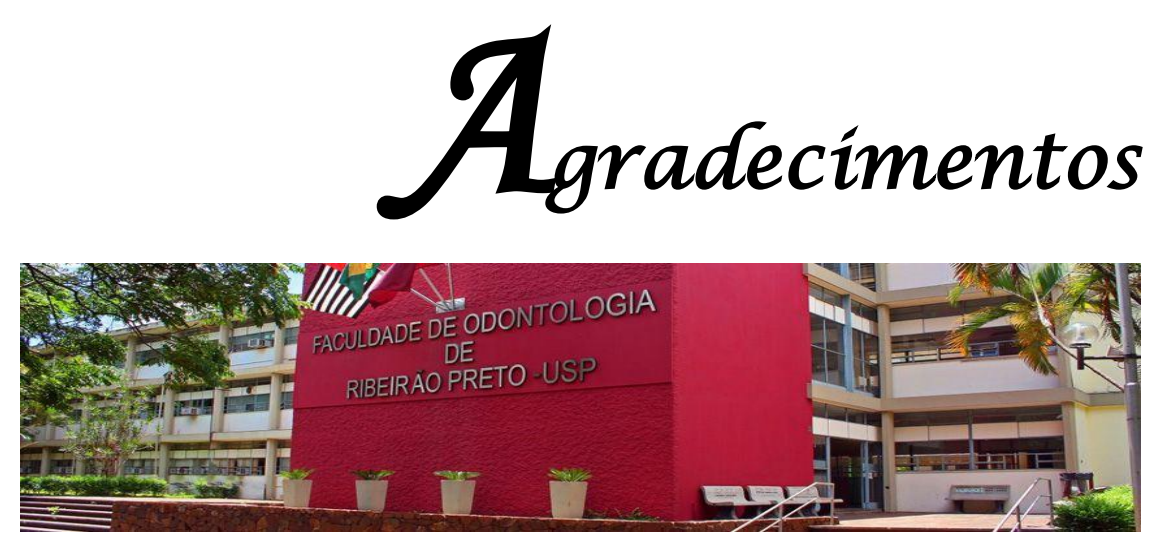

Ao Prof. Dr. Paulo César Saquy, por todo conhecimento compartilhado, pela orientação na carreira científica e acadêmica.

Ao Prof. Dr. Manoel Damião de Sousa Neto, pelo conhecimento científico transmitido, pelas oportunidades concedidas e pela contribuição na realização desta dissertação.

Ao Prof. Dr. Harley Francisco de Oliveira, e ao funcionário Rodrigo Santos do Departamento de Clínica Médica, da Faculdade de Medicina de Ribeirão Preto da Universidade de São Paulo, pela disponibilidade do equipamento para irradiação dos dentes, apoio dentro do Serviço de Radioterapia e pelos conhecimentos compartilhados.

À Prof. Dra. Alexandra Mussolino de Queiroz, pela contribuição na realização desta dissertação.

Ao Prof. Dr. Luís Eduardo Silva Soares, ao Prof. Dr. Airton Martin e à funcionária Allinne Ferrara do Instituto de Pesquisa de Desenvolvimento, da Universidade do Vale do Paraíba, pela disponibilidade do equipamento de Espectroscopia Raman Confocal, pela imensa ajuda, colaboração e conhecimentos compartilhados.

À Profa. Dra. Regina Guenka Palma Dibb, professora que, com toda calma e sabedoria, sempre foi uma grande colaboradora em momentos de dificuldade. Obrigada por todo conhecimento transmitido. 
À Profa. Dra. Débora Fernandes Costa Guedes, técnica do Laboratório de Gerenciamento de Resíduos Químicos/FORP-USP, pela convivência e oportunidades de aprendizado.

Aos Docentes do Departamento de Odontologia Restauradora da Faculdade de Odontologia de Ribeirão Preto - Universidade de São Paulo, pelos conhecimentos transmitidos e acolhimento.

Ao funcionário Carlos Feitosa dos Santos, exemplo de eficiência e dedicação, pelas inúmeras ajudas e lembretes.

Ao funcionário Reginaldo Santana da Silva, pelo incentivo, colaboração, disponibilidade e boa vontade em ajudar.

À Fabiane Carneiro Lopes, Jardel Francisco Mazzi Chaves e Rodrigo Dantas Pereira por toda ajuda, companheirismo, orientação, e conhecimento à mim transmitidos durante toda essa fase. Vocês foram essenciais no desenvolvimento e conclusão deste trabalho.

Aos meus grandes amigos Daniel José Filizola de Oliveira e Paulo André Yamin que, além de contribuírem para a realização deste projeto, me apoiaram, incentivaram e proporcionaram muitos momentos de alegrias e lembranças inesquecíveis. Vocês são amigos para a vida toda! 
À minha amiga e companheira de apartamento, Caroline Cristina Borges, pela amizade, companheirismo, apoio e experiências de vida trocadas.

Aos amigos da Pós-Graduação Amanda Buosi de Biagi, Bruno Monguilhott Crozeta, Bruno Henrique Figueiredo Matos, Fernanda Plotegher, Flávia Cássia Cabral Rodrigues, Gabriela Arantes da Conceição Sturaro, Graziela Bianchi Leoni, Igor Bassi Ferreira Petean, Isabela Lima de Mendonça, Isadora Mello Vilarinho Soares, Júlia Adornes Gallas, Larissa Ernesto Pereira, Luis Eduardo Souza Flamini, Rafael Souza Assis e Reinaldo Dias da Silva Neto por todos os conhecimentos, ensinamentos, experiências e risadas compartilhadas.

Aos funcionários Frederico Augusto Farias, Luiza Godoi Pitol e Rosângela Angelini, pelo convívio diário, apoio e solicitude.

Aos familiares, que sempre me ajudaram e apoiaram, ajudando a vencer mais essa etapa da minha vida.

À CAPES - Coordenação de Aperfeiçoamento de Pessoal de Nível Superior, pela ajuda financeira.

À Universidade do Vale do Paraíba, pela oportunidade de poder usufruir da estrutura impecável de altíssimo nível que foi essencial para a realização deste trabalho e para o meu crescimento profissional.

À Faculdade de Odontologia de Ribeirão Preto da Universidade de São Paulo, que me concedeu o privilégio e honra de realizar meu mestrado. 

"Comece fazendo o que é necessário, depois o que é possivel, $e$ de repente você estará fazendo $\sigma$ impossivel"

(São Franciscode Assis) 


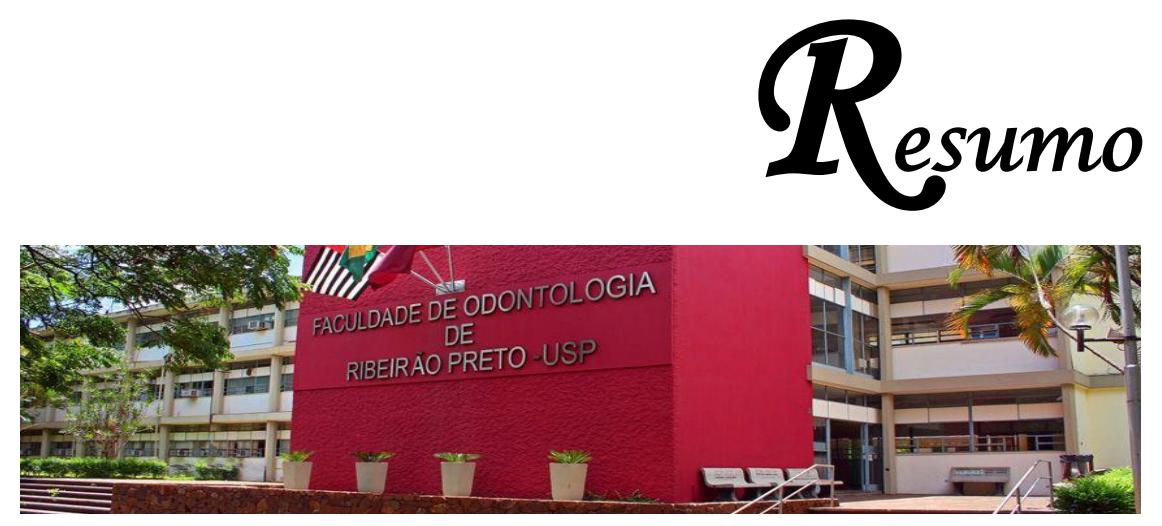

CAMPI, L. B. Efeito da irradiação gama na composição química da dentina radicular. 2017 95p. Dissertação (Mestrado) - Faculdade de Odontologia de Ribeirão Preto, Universidade de São Paulo, Ribeirão Preto, 2017.

O presente estudo avaliou a composição química da dentina radicular de dentes submetidos à radioterapia por meio de Espectroscopia Raman Confocal (ERC). Vinte pré-molares inferiores humanos homólogos foram selecionados e distribuídos em dois grupos $(n=10)$ de acordo com a irradiação: não irradiados e irradiados, submetidos à radioterapia fraccionada com raios-X de $6 \mathrm{MV}$. Os dentes foram seccionados e submetidos à análise da composição química da dentina radicular submetida à radioterapia por meio de ERC, em relação aos picos de fosfato, carbonato e amidas I, II e III. Foi utilizada objetiva de 40x (Olympus), com luz de comprimento de onda de $785 \mathrm{~nm}$, compreendendo a faixa espectral de 400 - 1800 $\mathrm{cm}^{-1}$, na região de baixa frequência, com resolução espacial de $2 \mu \mathrm{m}$. Para a geração do espectro, a potência do laser utilizada foi de $21 \mathrm{~mW}$ e o tempo de exposição de 5 segundos. A intensidade dos picos fosfato $-\mathrm{PO}_{4}{ }^{3-}\left(590 \mathrm{~cm}^{-1}\right) \mathrm{e}$ carbonato $-\mathrm{CO}_{3}{ }^{2-}\left(1070 \mathrm{~cm}^{-1}\right)$ no $\mathrm{ERC}$ são proporcionais à quantidade de conteúdo inorgânico, enquanto que a amida I $\left(1670 \mathrm{~cm}^{-1}\right)$, II $\left(1453 \mathrm{~cm}^{-1}\right)$ e III $\left(1267 \mathrm{~cm}^{-1}\right)$ são proporcionais ao conteúdo orgânico (colágeno). Os dados obtidos foram submetidos à análise estatística $(T e s t e \mathrm{~T}, \mathrm{P}<0,05)$ para amostras independentes, avaliando-se a influência da radioterapia nos valores de fosfato, carbonato e amidas I, II e III em diferentes regiões radiculares. Em região de dentina radicular intracanal, o grupo irradiado $(1,23 \pm 0,06)$ apresentou menores valores de fosfato quando comparado ao grupo não irradiado $(1,40 \pm 0,18)(P<0,05)$. Em relação ao carbonato, foi observado que os dentes irradiados $(1,56 \pm 0,06)$ apresentaram menores valores quando comparados ao grupo não irradiado $(1,42 \pm 0,10)(P<0,05)$. Para os picos de amida, não foi observada diferença estatística entre os grupos em amida I $(P=0,295)$ e amida II ( $P=0,792)$. No entanto, o tratamento radioterápico reduziu significativamente os valores de amida III do grupo irradiado $(1,05 \pm 0,19)$ em comparação ao grupo não irradiado $(1,28 \pm 0,24)$. Quando avaliada a região da dentina radicular média, o grupo irradiado $(1,30 \pm 0,12)$ apresentou menores valores de fosfato quando comparado ao grupo não irradiado $(1,48 \pm 0,22)(P<0,05)$; e em relação aos valores de carbonato $(P=0,859)$, amida I ( $P=0,785)$, amida II $(P=0,771)$ e amida III $(P=0,338)$ não foi observada diferença estatística entre eles. $\mathrm{Na}$ análise em cemento, não houve diferenças estatísticas entre os grupos irradiado e não irradiado para os valores de fosfato $(P=0,448)$, carbonato $(P=0,575)$ e amida I $(P=0,225)$, amida II $(P=0,437)$ e amida III $(P=0,187)$. Dessa forma, pode-se concluir que a radioterapia promoveu alterações nos picos de amida III, indicando modificação estrutural do colágeno.

Palavras-chave: Espectroscopia Raman Confocal; Radioterapia; Dentina. 



\section{$\mathcal{A}_{\text {sstract }}$}

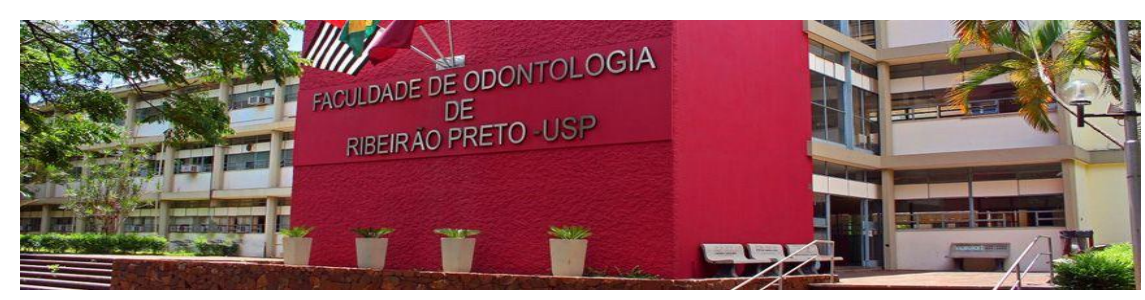



CAMPI, L.B. Gamma irradiation effect on the root dentin chemical composition. 2017, 95p. Dissertação (Mestrado) - Faculdade de Odontologia de Ribeirão Preto, Universidade de São Paulo, Ribeirão Preto, 2017.

The present study was to evaluate the root dentin chemical composition of teeth submitted to radiotherapy by Confocal Raman Spectroscopy (CRS). Twenty inferior human homologues premolars were selected and divided in two groups $(n=10)$ according to the irradiation protocol: non Irradiated and irradiated, submitted to fractional X-ray radiotherapy of $6 \mathrm{MV}$. The teeth were sectioned and submitted to the analysis of the chemical composition of radicular dentin submitted to radiotherapy by CRS, evaluating the phosphate, carbonate and amides I, II and III peaks. A 40x objective (Olympus) was used, generating a light with a $785 \mathrm{~nm}$ wavelength, comprising the spectral range of $400-1800 \mathrm{~cm}^{-1}$ in the low frequency region with spatial resolution of $2 \mu \mathrm{m}$. For the spectrum generating the laser power used was 21 $\mathrm{mW}$ and the exposure time was 5 seconds. The intensity of the phosphate $-\mathrm{PO}_{4}{ }^{3-}$ $\left(590 \mathrm{~cm}^{-1}\right)$ and carbonate $-\mathrm{CO}_{3}{ }^{2-}\left(1070 \mathrm{~cm}^{-1}\right)$ peaks in the CRS are proportional to the amount of inorganic content while the amide I $\left(1670 \mathrm{~cm}^{-1}\right)$, II $\left(1453 \mathrm{~cm}^{-1}\right)$ and III $\left(1267 \mathrm{~cm}^{-1}\right)$ are proportional to organic content (collagen). The data were submitted to statistical analysis (Test $\mathrm{T}, \mathrm{P}<0.05)$ for independent samples, evaluating the influence of radiotherapy on the phosphate, carbonate and amide I, II and III values in different root regions. In the intracanal dentin root region, the irradiated group (1.23 \pm 0.06 ) had lower phosphate values when compared to the non-irradiated group $(1.40 \pm 0.18)(P<0.05)$. In relation to the carbonate, it was observed that the irradiated teeth $(1.56+0.06)$ had lower values than the non-irradiated group $(1.42+$ $0.10)(P<0.05)$. The amide peaks has no statistical difference observed between the groups in relation to the amide I $(P=0,295)$ and amide II $(P=0,792)$. However, the radiotherapeutic treatment significantly reduced the amide III values of the irradiated group $(1.05+0.19)$ compared to the non-irradiated group $(1.28+0.24)$. When the middle radicular dentin region was evaluated, the irradiated group $(1.30 \pm 0.12)$ had lower phosphate values when compared to the non-irradiated group $(1.48 \pm 0.22)$ $(P<0.05)$; and in relation to the carbonate $(P=0.859)$, amide I $(P=0.785)$, amide II $(P=0,771)$ and amide III $(P=0,338)$ peaks no statistical difference was showed between irradiated and non-irradiated teeth. In the cement analysis, there was no statistical difference between the irradiated and non-irradiated groups for the phosphate $(p=0.448)$, carbonate $(P=0.575)$, amide I $P=0.225)$, amide II $(P=0,437)$ and amide III $(P=0,187)$ values. In conclusion, the radiotherapy was able to promote alterations in the amide III, changing the collagen structure.

Key words: Confocal Raman Spectroscopic; Radiotherapy; Dentin 


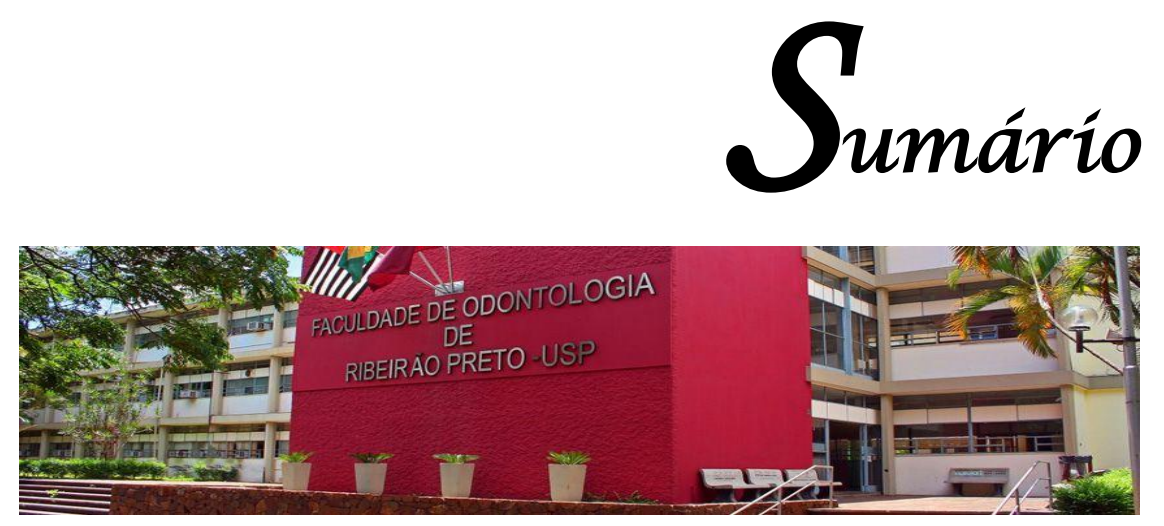

SUMÁRIO

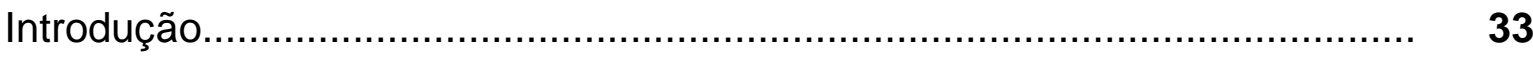

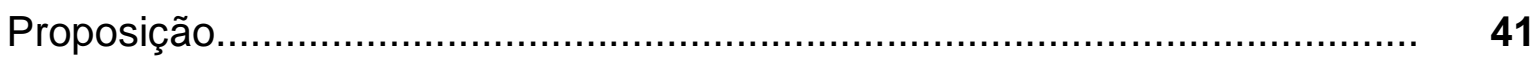

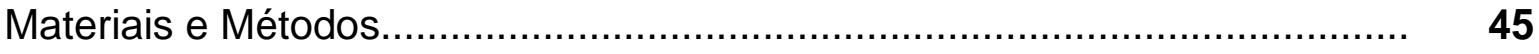

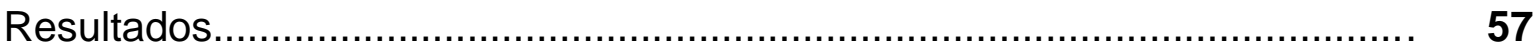

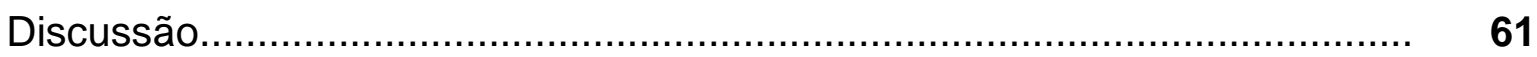

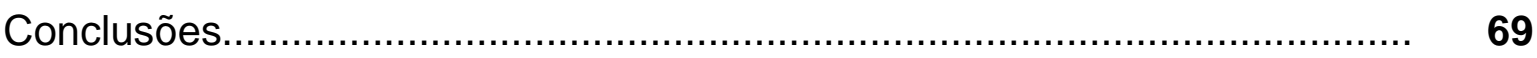

Referências Bibliográficas.......................................................................... 73

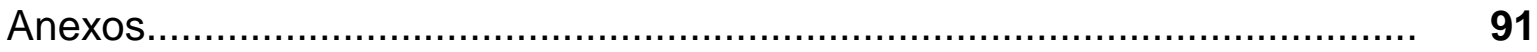





\section{$\Gamma_{\text {ntrodução }}$}

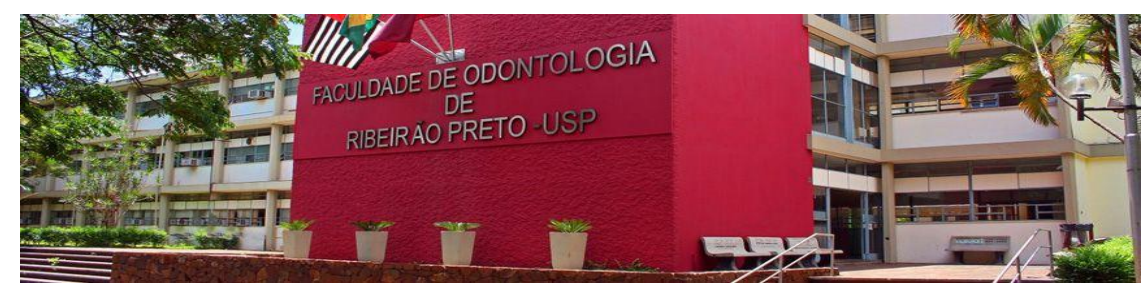



A cada ano, estima-se o surgimento de 416,05 novos casos de câncer a cada 100 mil habitantes, sendo que o câncer de cabeça e pescoço representa aproximadamente 13,6\% (INCA, 2016), ocupando a sétima posição das neoplasias mais encontradas no mundo, com incidência anual aproximada de 640 mil casos (GLOBOCAN, 2016; INCA, 2016; LO et al., 2016; NESS-JENSEN et al., 2016), sendo 19 mil encontrados no Brasil (INCA, 2016). O câncer de cabeça e pescoço compreende um grupo heterogêneo de tumores que acometem a cavidade bucal, laringe, faringe, tireoide, lábios, boca, cavidade nasal, seios paranasais e glândulas salivares (LOTHAIRE et al., 2006; JEMAL et al., 2008; COLOMBO; RAHAL, 2009; LIESHOUT; BOTS, 2014; GAUDET et al., 2015; STENSON; POON, 2016; YAP et al., 2016).

O tratamento para o câncer de cabeça e pescoço depende de fatores como o tipo de câncer, o estadiamento e a localização (BESSEL et al., 2011), podendo ser realizado através de cirurgias, radioterapia, quimioterapia ou pela combinação destes (BEUMER; CURTIS; MARUNICK, 1996; AÇIL et al., 2007; ROSALES et al., 2009; GONÇALVES et al., 2014; LIESHOUT; BOTS, 2014; GUPTA et al., 2015; MARTINS et al., 2016), sendo a radioterapia amplamente utilizada tanto como terapia primária, coadjuvante ou como tratamento paliativo em estágios finais e inoperáveis da doença (SOARES et al., 2010; BESSEL et al., 2011; CHAACHOUAY et al., 2011; SOARES; NEIVA; SOARES, 2011; GONÇALVES et al., 2014; ARID, 2015; MARTINS et al., 2016).

A radioterapia utiliza elementos radioativos e radiações de alta energia produzidas por equipamentos de raios-X e aceleradores de partículas (INCA, 1993; CHAACHOUAY et al., 2011; MARTINS et al., 2016; VIEIRA et al., 2016; WALTER et al., 2016) que agem de forma direta ao promover ruptura das cadeias do ácido 
desoxirribonucleico, ou indireta na produção de radicais livres que levam a necrose celular (GUY POYTO, 1989; PIOCH et al., 1992; KHAW et al., 2014; MARTINS et al., 2016). Durante a radioterapia para o câncer de cabeça e pescoço, dificilmente os tecidos circunvizinhos sadios, como ossos, mucosa, dentes e glândulas salivares, são preservados (THIAGARAJAN; IYER, 2014; JAGUAR et al., 2015; AGARWAL; SHIVA; KUMAR; RAI, 2016; ROŚ-MAZURCZYK et al., 2016; CARRARACOTOMACIO et al., 2017).

O regime radioterápico mais aceito para o tratamento de neoplasias malignas de cabeça e pescoço é o fracionamento convencional que consiste na aplicação de doses diárias de 1,8 a 2 Gy, 5 ciclos na semana, por 6 semanas, totalizando de 54 a 60 Gy (FLETCHER, 1988; BEUMER; CURTIS; MARUNICK, 1996; SEIKALY et al., 2004; JHAM; FREIRE, 2006; KIELBASSA; HELLWIG; MEYER-LÜCKEL, 2006; NUTTING et al., 2011; GONÇALVES et al., 2014; LIESHOUT; BOTS, 2014; DE SÁ FERREIRA et al., 2016; MARTINS et al., 2016; MISHRA et al., 2016), com o intuito de minimizar os efeitos colaterais da radiação ao permitir o reparo dos tecidos normais e estruturas circunvizinhas (FERGUSON; STEVENS, 2007; NAVES et al., 2012; DE SÁ FERREIRA et al., 2016; MARTINS et al., 2016; MISHRA et al., 2016).

$\mathrm{Na}$ cavidade bucal, os efeitos colaterais podem assumir caráter imediato como dor e sensibilidade nos tecidos moles, alteração quali-quantitativa da saliva, perda de paladar, infecções fúngicas e mucosite, ou ainda caráter tardio, como xerostomia, osteorradionecrose dos maxilares, atrofia muscular, trismo e alterações na microflora bacteriana (JANSMA et al., 1988; KIELBASSA et al., 1997; FERGUSON; STEVENS, 2007; KHAW et al., 2014; KUGA et al., 2014; AGARWAL; SHIVA KUMAR; RAI, 2016; DE SÁ FERREIRA et al., 2016; CARRARACOTOMACIO et al., 2017). 
Em esmalte e dentina, a literatura tem demonstrado que a radiação gama pode causar redução da microdureza (KIELBASSA et al., 1997; KIELBASSA et al., 1999; KIELBASSA et al., 2002; LIESHOUT; BOTS, 2014), obliteração dos túbulos dentinários (GRÖTZ et al., 1997; GONÇALVES et al., 2014), degeneração dos processos odontoblásticos (GRÖTZ et al., 1997; LIESHOUT; BOTS, 2014) e das fibras de colágeno (SPRINGER et al., 2005; LIESHOUT; BOTS, 2014; REED et al., 2015; MARTINS et al., 2016). Além disso, ocorre fibrose pulpar secundária à redução da vascularização pulpar e do metabolismo odontoblástico (SPRINGER et al., 2005; KATAOKA et al., 2012).

A dentina é um tecido mineralizado composto de aproximadamente $70 \%$ de material inorgânico, 20\% de material orgânico e 10\% de água, adsorvida na superfície do mineral ou nos interstícios dos cristais (MJÖR, 2009). A matriz inorgânica consiste em hidroxiapatita em pequenas lâminas, sendo a principal responsável por conferir dureza; enquanto a matriz orgânica consiste em $90 \%$ de colágeno principalmente do tipo I, com pequenas quantidades dos tipos III e V, e substância fundamental amorfa (proteoglicanos e glicosaminoglicanos), estando relacionada à resistência e elasticidade da estrutura dental (ANGKER et al., 2004; MJÖR, 2009; DA SILVA; PENNA, 2012).

A hidroxiapatita - $\mathrm{Ca}_{10}\left(\mathrm{PO}_{4}\right)_{6}(\mathrm{OH})_{2}$ - apresenta 39,9\% de cálcio, 18,5\% de fósforo e 3,38\% de grupo hidroxila dispostos em uma estrutura iônica que permite a permutação considerável em sua composição através de substituições catiônicas e aniônicas isomorfas (NANCl, 2013). Essas substituições podem alterar a cristalinidade, os parâmetros de rede, as dimensões dos cristais, a textura superficial, a estabilidade e a solubilidade da estrutura da hidroxiapatita (DE MELO COSTA et al., 2009). Assim, cada cristal de apatita está disponível para trocas 
iônicas, de forma que o carbonato pode ser substituto para as posições da hidroxila e do fosfato ( $\mathrm{NANCl}, 2013)$. O fosfato presente na matriz inorgânica é considerado aglutinador (DE MELO COSTA et al., 2009), enquanto o carbonato é o responsável por proporcionar maior solubilidade aos tecidos (SONJU; RUYTER, 1997; NANCI, 2013; DE SÁ FERREIRA et al., 2016).

Já o colágeno é uma proteína fibrosa composta por cadeias peptídicas de aminoácidos como glicina, prolina, lisina, hidroxilisina, hidroxiprolina e alanina, organizadas paralelamente à um eixo, formando as fibras de colágeno, que conferem resistência e elasticidade ao substrato dental (DA SILVA; PENNA, 2012). As moléculas de aminoácidos são unidas por meio de ligações peptídicas covalentes entre o grupo carboxílico $(\mathrm{COOH})$ com o grupo amina $\left(\mathrm{NH}_{2}\right)$ (DA SILVA; PENNA, 2012). A estrutura formada pelo colágeno e hidroxiapatita proporciona algumas propriedades à dentina como a capacidade de absorver e adsorver moléculas (MAVROPOULOS et al., 2002).

As alterações quantitativas e qualitativas da saliva e da microbiota bucal, bem como as alterações químicas e estruturais em esmalte e dentina somadas à dificuldade de higienização da cavidade bucal, devido ao desenvolvimento de mucosites e rigidez muscular (JANSMA et al., 1990; KIELBASSA, 2000; VISSINK et al., 2003; KIELBASSA; HELLWIG; MEYER-LÜCKEL, 2006), favorecem 0 aparecimento e progressão da cárie de radiação (VISSINK et al., 2003; SPRINGER et al., 2005; KIELBASSA; HELLWIG; MEYER-LÜCKEL, 2006; SHENOY; SHENOY; SHETTY, 2007; SILVA et al., 2009; GUPTA et al., 2015; SøNSTEVOLD; JOHANNESSEN; STUHR, 2015; DOBROŚ et al., 2016; LIANG et al., 2016).

A cárie de radiação é uma doença complexa e destrutiva, de origem multifatorial (GONÇALVES et al., 2014; MARTINS et al., 2016), que difere das 
lesões de cárie convencionais por apresentar rápida progressão e atingir superfícies normalmente livres de cárie, como pontas de cúspides e faces dentais livres (KIELBASSA; HELLWIG; MEYER-LÜCKEL, 2006; SILVA et al., 2009; BEECH et al., 2014; GUPTA et al., 2015; MARTINS et al., 2016), levando à severa destruição dos tecidos dentais mineralizados (AL-NAWAS et al., 2000) e consequentemente alterações pulpares (SPRINGER et al., 2005; SHENOY; SHENOY; SHETTY, 2007; BEECH et al., 2014). No entanto, ainda não há consenso sobre como a estrutura dental é alterada pela radioterapia (LIESHOUT; BOTS, 2014; RODRIGUES, 2015).

A inovação tecnológica e o aprimoramento no tratamento do câncer de cabeça e pescoço têm propiciado aumento da sobrevida e melhoria da qualidade de vida dos pacientes afetados (GAUDET et al., 2015; MARTINS et al., 2016; STENSON; POON, 2016). Entretanto, a alta prevalência da cárie de radiação ainda é um desafio e pode refletir na necessidade de tratamento endodôntico e procedimentos restauradores. Neste sentido, torna-se importante conhecer detalhadamente os efeitos da radiação sobre a composição química da dentina, visando melhor abordagem desses pacientes em relação à prevenção, bem como o correto planejamento e desenvolvimento de estratégias para a realização do procedimento restaurador. 



\section{Proposição}

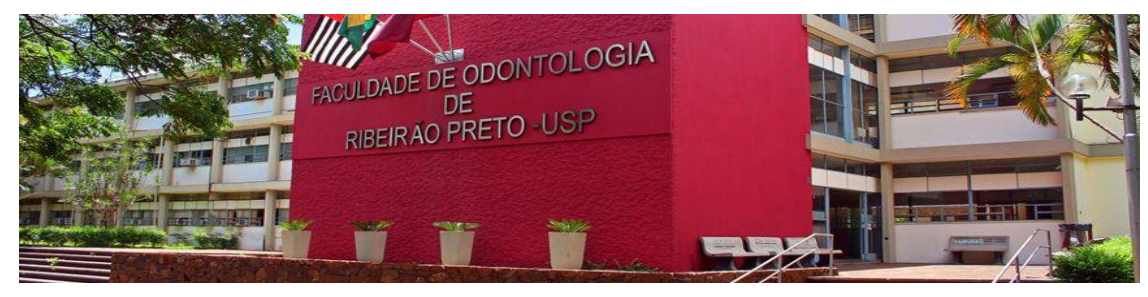



A proposta do presente estudo foi avaliar a composição química da dentina radicular submetida à radioterapia por raios $\mathrm{X}$ de $6 \mathrm{MV}$, em regime fracionado (2 Gy, por 5 dias consecutivos, durante 6 semanas, totalizando 30 ciclos e 60 Gy), com relação aos picos de fosfato, carbonato e amidas I, II e III, por meio de Espectroscopia Raman Confocal. 



\section{Materiais e Métodos}

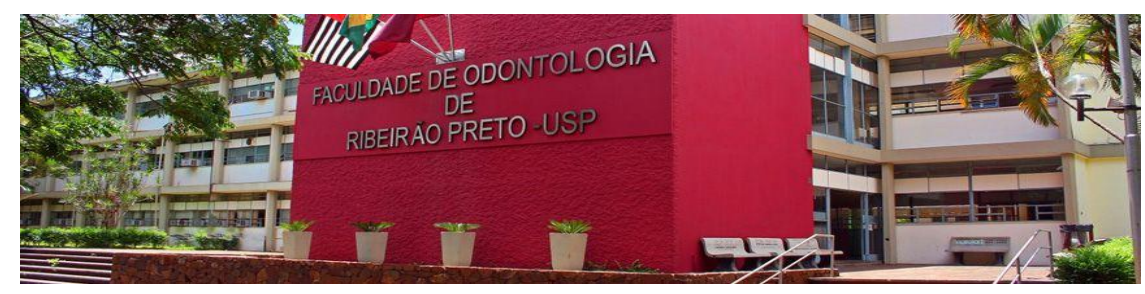





\section{Seleção da amostra}

Após revisão e aprovação do presente estudo pelo Comitê de Ética em Pesquisa da Faculdade de Odontologia de Ribeirão Preto da Universidade de São Paulo (CEP/FORP-USP), pelo parecer no 1.613 .009 e CAAE $n^{\circ}$ 56735816.1.0000.5419, foram obtidos, do Biobanco de Dentes Humanos da FORPUSP, pré-molares humanos hígidos e homólogos entre si.

Os dentes foram examinados por meio de estereomicroscópio (Leica, M165C, Leica Microsystems, Alemanha), com o software LAS v4.4 (Leica, M165C, Leica Mycrosystems, Alemanha) e radiografados individualmente, nos sentidos orto e mesiorradial com filme Ektaspeed EP (Kodak Brasileira Comércio e Indústria Ltda, São José dos Campos, SP, Brasil), tempo de exposição de 0,5 segundo e distância foco-filme de $10 \mathrm{~cm}$. As radiografias foram avaliadas com auxílio de negatoscópio (Konex, Konex Ind. e Com. de Metais LTDA, São Paulo, SP, Brasil) e de aparato visualizador magnificador (X-Produkter, Malmö, Suécia).

Após exame macroscópico e radiográfico, foram selecionados 20 pré-molares inferiores humanos homólogos (Figura 1). Os critérios de exclusão estabelecidos foram: rizogênese incompleta, presença de mais de um canal, raiz e canal com curvatura moderada ou acentuada, calcificações na câmara pulpar, reabsorções internas, trincas e fraturas, tratamento endodôntico prévio e presença de restaurações metálicas devido à interferência destas durante a radioterapia.

Os dentes foram lavados em água corrente durante 24 horas e tiveram sua superfície externa limpa por meio de raspagem ultrassônica (Profi II Ceramic, Dabi Atlante Ltda, Ribeirão Preto, SP, Brasil). Em seguida, foram inseridos em tubos de eppendorf contendo saliva artificial, com $\mathrm{pH} 7$, renovada diariamente, e armazenados em estufa $\left(37^{\circ} \mathrm{C}, 100 \%\right.$ umidade). 


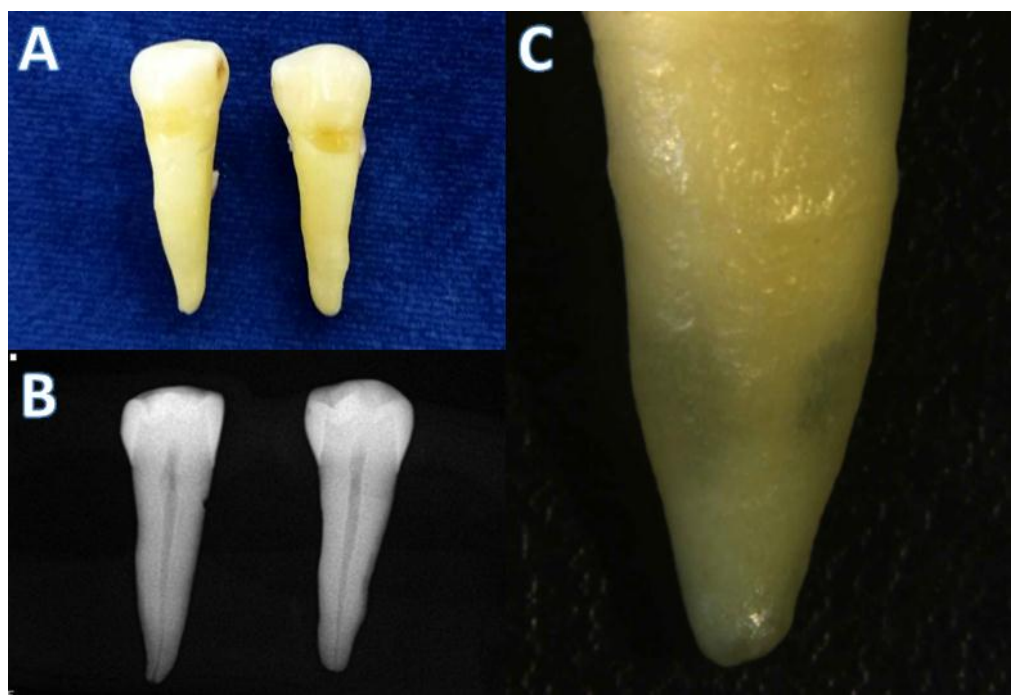

Figura 1. (A) Pré-molares homólogos selecionados; (B) Seleção radiográfica; (C) Análise visual em estereomicroscópio.

Em seguida, as amostras foram distribuídas em 2 grupos $(n=10)$ de acordo com o regime radioterápico: Grupo I - não irradiados; e Grupo II - irradiados, submetidos à radioterapia fraccionada com raios-X de $6 \mathrm{MV}$, conforme fluxograma apresentado na Figura 2.

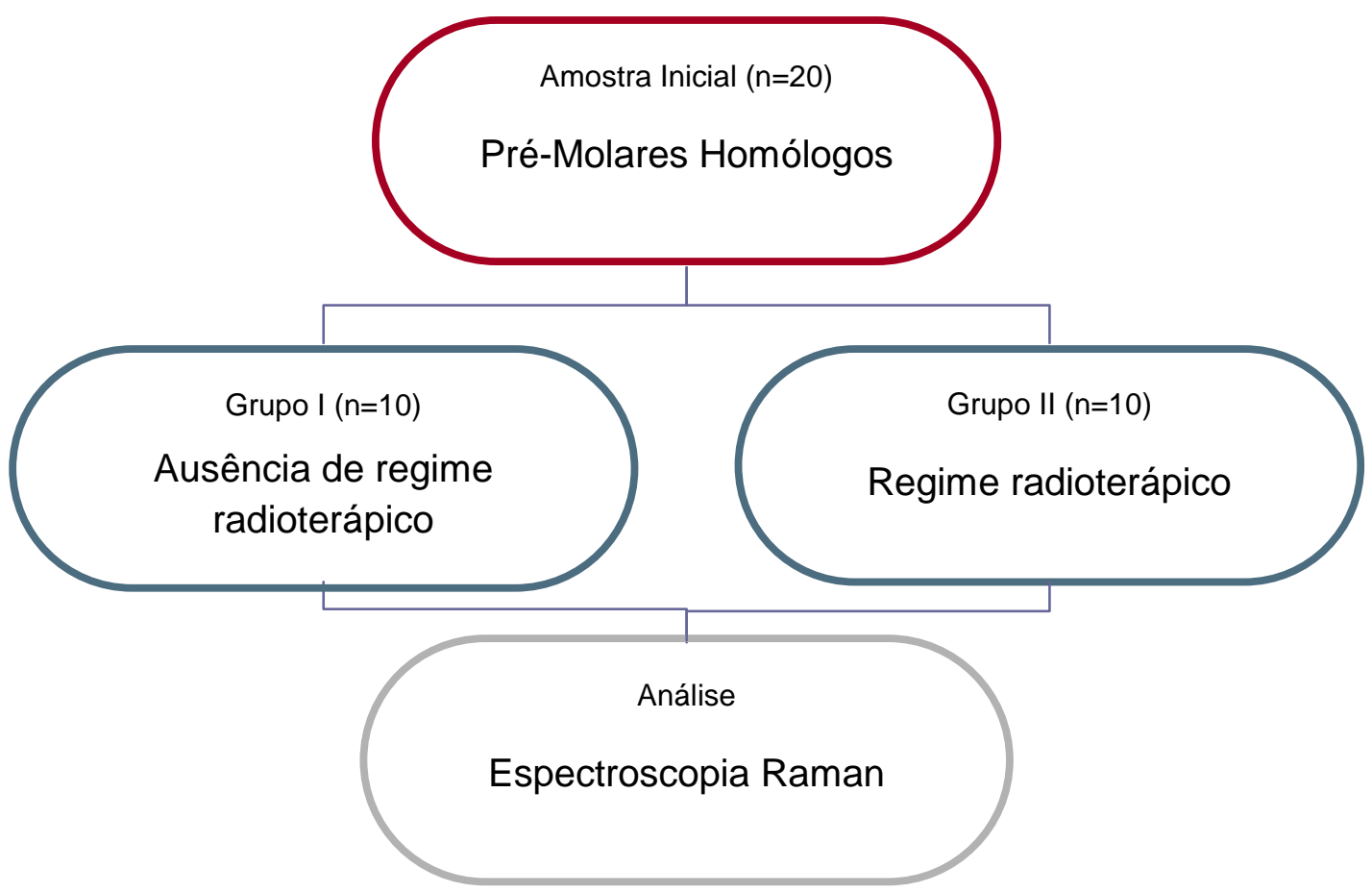

Figura 2. Fluxograma dos grupos e subgrupos experimentais. 
Para a irradiação, todos os dentes foram dispostos em suporte plástico, com o longo eixo paralelo ao solo a fim de possibilitar que a irradiação direta permanecesse a mesma por unidade de área. Com o intuito de mantê-los em ambiente úmido, simulando as características da cavidade bucal, o suporte plástico foi preenchido com água destilada, recobrindo totalmente todos os dentes (Figura $3 A)$.

Os dentes foram irradiados por raios-X de $6 \mathrm{MV}$ em regime fracionado de 2 Gy, por 5 dias consecutivos, com 30 ciclos, durante 6 semanas, perfazendo 60 Gy. Foi utilizado o acelerador linear de raios-X RS 2000 (Rad Fonte Technologies, Inc., Suwanee, GA, EUA) (Figura 3B) com energia de $200 \mathrm{kVp}$ e 25 mA e filtro padrão de $\mathrm{Cu}$ de 0,3 mm, dedicado a Pesquisas Biológicas, no Serviço de Radioterapia do Hospital das Clínicas da Faculdade de Medicina de Ribeirão Preto - Universidade de São Paulo. Os raios-X gerados sob estes parâmetros apresentam espectro com energia entre $95 \mathrm{kV}$ e $200 \mathrm{kV}$. O gradiente de dose em tecidos é o equivalente a cerca de $10 \%$ e $0,5 \mathrm{~cm}$ de profundidade.

O suporte plástico foi alinhado de forma equidistante ao centro do feixe e dentro do cone para garantir uma taxa de dose uniforme (aproximadamente 2,85 Gy/minuto) e entrega total da dose por fração. O controle de qualidade foi realizado utilizando o dosímetro Nanodot (Landauer, Inc., Glenwood, IL, EUA), sendo as leituras de dose na superfície do suporte plástico utilizadas para calcular os tempos de tratamento "beam-on". Os dosímetros foram colocados abaixo do suporte plástico irradiado e calibrados de acordo com as condições do feixe descritas anteriormente.

No período entre os ciclos de irradiação, os dentes foram novamente armazenados em tubos eppendorf com saliva artificial, renovada diariamente, e mantidos em estufa $\left(37^{\circ} \mathrm{C}, 100 \%\right.$ umidade), em um total de 30 ciclos durante 6 semanas (MARTINS et al., 2016). 


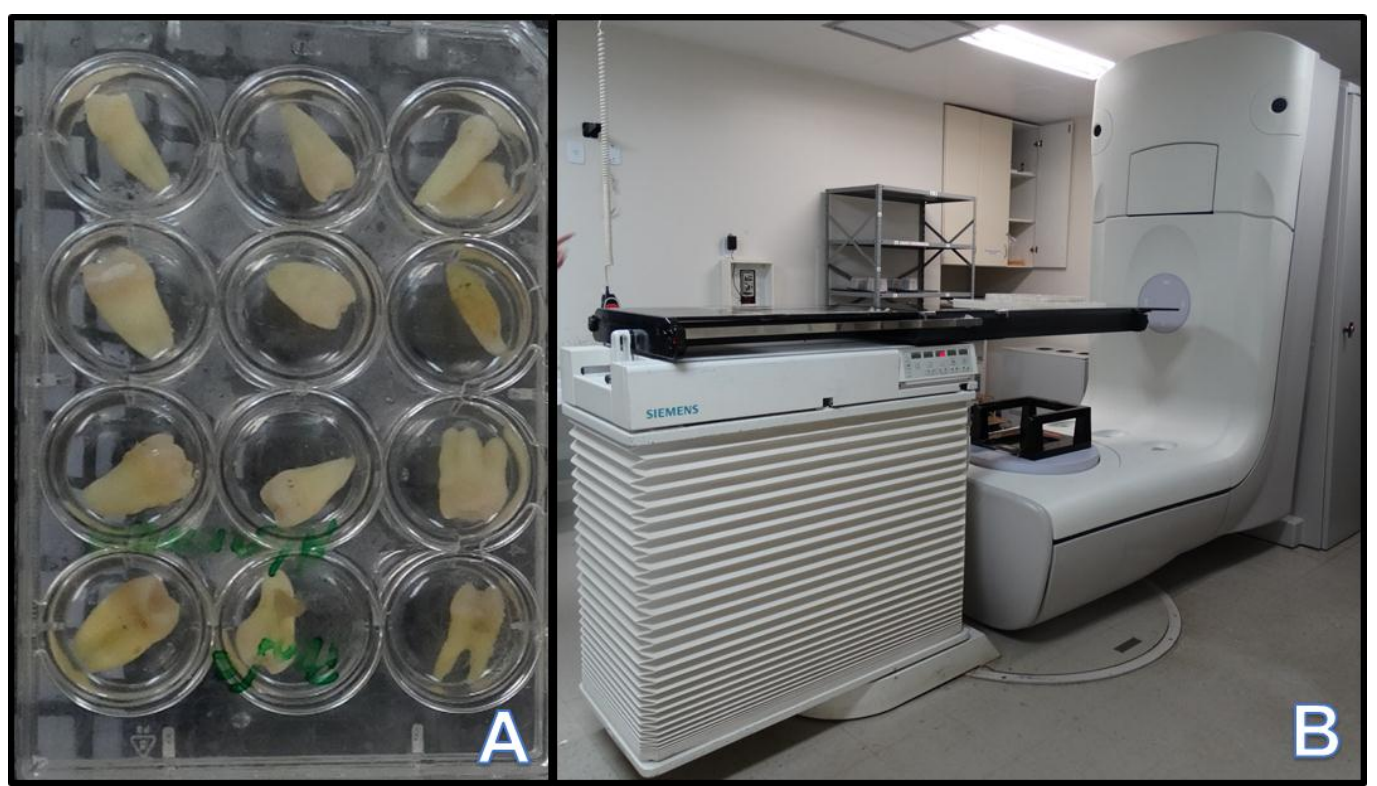

Figura 3. (A) Suporte plástico com os dentes paralelos ao solo imersos em água destilada; (B) Acelerador linear de raios-X RS 2000 (Rad Fonte Technologies, Inc., Suwanee, GA, EUA), dedicado a Pesquisas Biológicas, do Serviço de Radioterapia do Hospital das Clínicas da Faculdade de Medicina de Ribeirão Preto- Universidade de São Paulo.

\section{Preparo dos Espécimes}

Os dentes foram posicionados em placas de resina acrílica, com o eixo longitudinal paralelo à superfície das mesmas e fixados com cola quente. As placas foram individualmente acopladas à máquina de cortes Isomet 1000 (Buehler, Lake Forest, IL, EUA) e os dentes foram seccionadas paralelamente ao seu longo eixo no sentido vestíbulo-lingual (Figura 4A) com disco diamantado de $0,5 \mathrm{~mm}$ de espessura e peso de $75 \mathrm{~g}$ (South Bay Technology, San Clement, CA, EUA), à velocidade constante de $300 \mathrm{rpm}$, sob refrigeração. Posteriormente, as amostras seccionadas (Figura 4B) foram novamente fixadas em placas de resina acrílica com o eixo longitudinal perpendicular à superfície das mesmas e fixadas com cola quente (Figura 4C). A raiz foi então seccionada em três terços: cervical, médio e apical e a coroa descartada (Figura 4D). Cada terço foi fixado com o eixo longitudinal paralelo à superfície da placa de resina acrílica e foram seccionados (Figura 4E), de forma a obter três espécimes de cada (Figura 4F). Desses espécimes, dois foram utilizados 
para análise no presente estudo, sendo um correspondente à dentina radicular intracanal e outro à dentina radicular média e cemento.

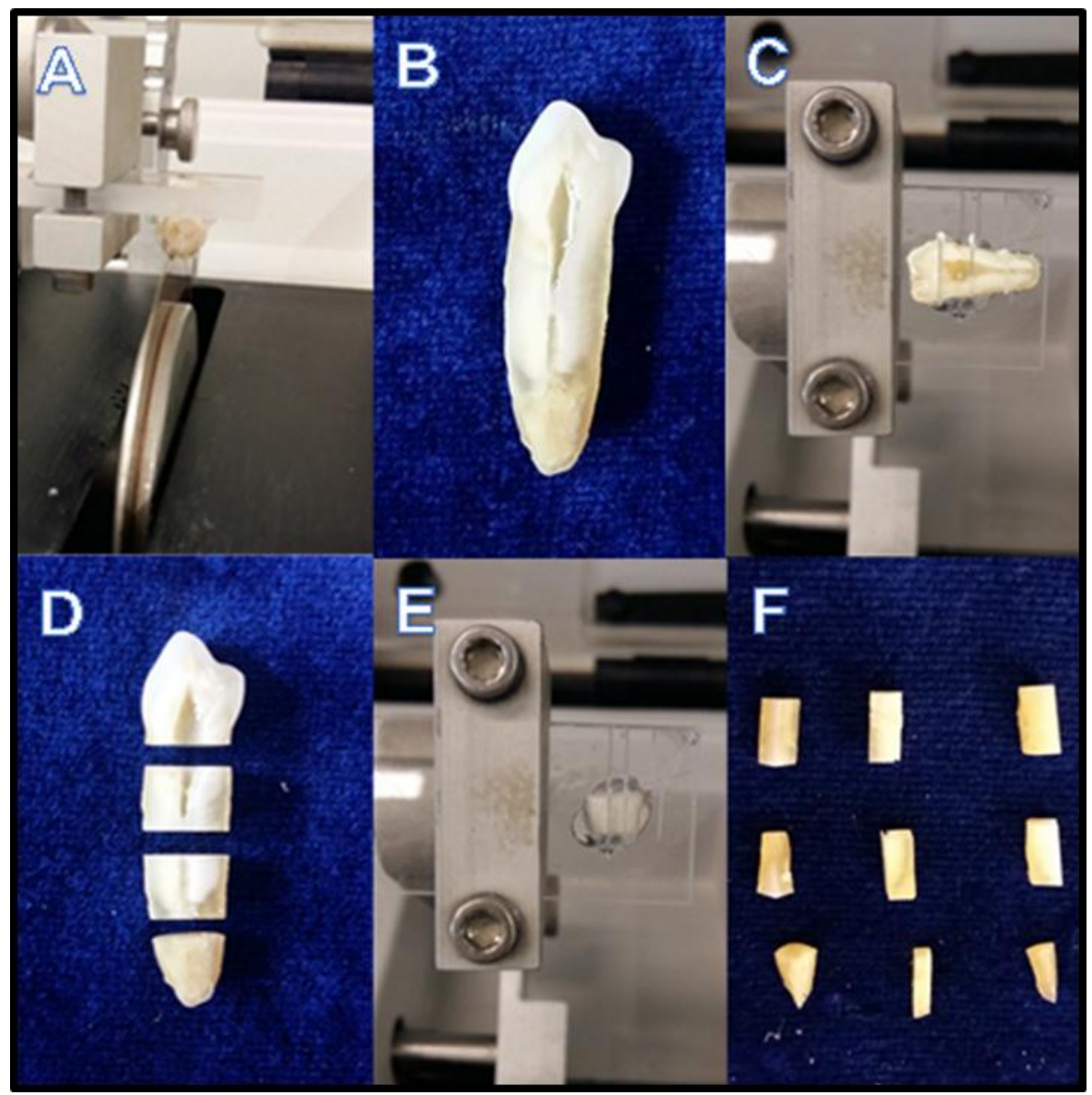

Figura 4. Representação esquemática da secção das amostras para obtenção dos espécimes. (A) Amostra posicionada em placas de resina acrílica, com o eixo longitudinal paralelo à superfície da mesma e fixada com cola quente. (B) Corte longitudinal. (C) Amostra posicionada em placas de resina acrílica, com o eixo longitudinal perpendicular à superfície da mesma e fixada com cola quente. (D) Amostra seccionada em coroa, terço cervical, terço médio e terço apical. (E) Cada terço foi fixado com o eixo longitudinal paralelo à superfície da placa de resina acrílica. (F) Três espécimes obtidos de cada terço.

Em seguida os corpos de prova foram posicionados em uma matriz e polidos com lixas d'água de abrasividade \#1200, em máquina politriz (Politriz Universal Aropol 2 V, Arotec, Cotia, São Paulo, Brasil), sob refrigeração abundante (Figura 5). Os espécimes foram então levados à cuba ultrassônica com água destilada e deionizada (Ultrasonic Clearner T-1449-D. Odontobrás Ind. e Com., 14075-060, Ribeirão Preto, SP, Brasil), onde foram mantidos por 5 minutos. 


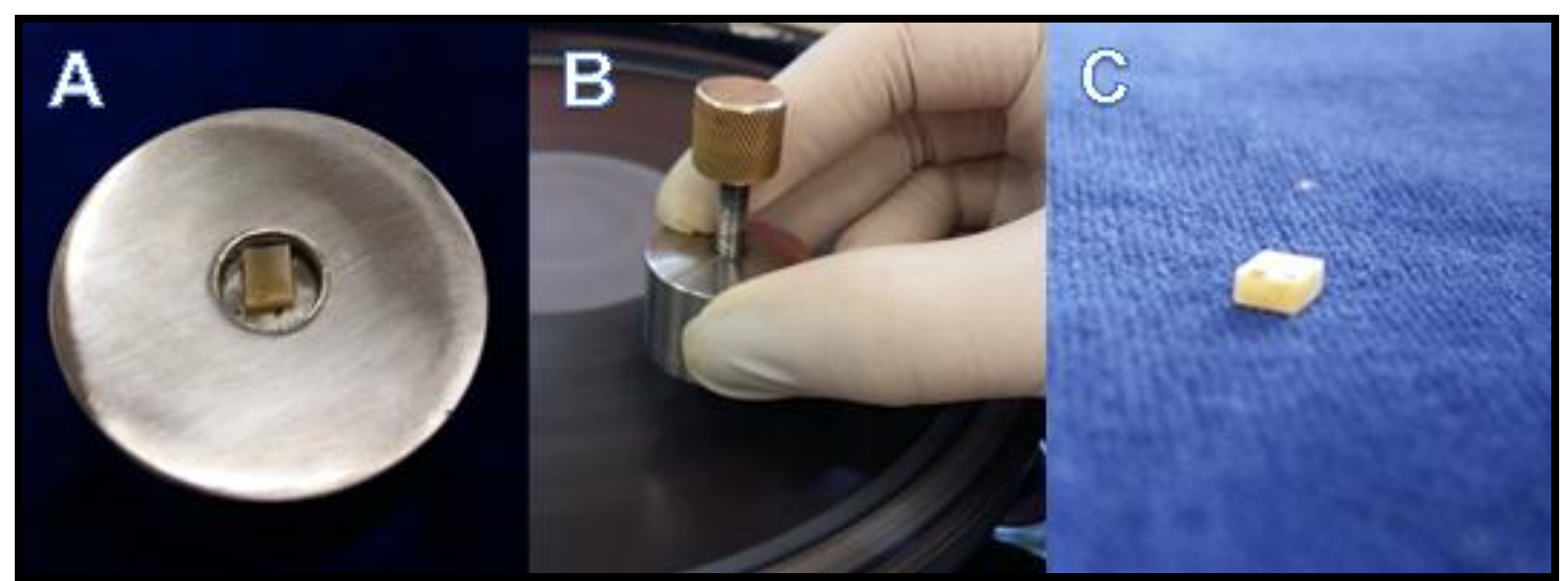

Figura 5. Polimento dos espécimes. (A) Espécime posicionado em matriz. (B) Politriz e lixa d'água \#1200. (C) Espécime polido.

\section{Análise da composição orgânica e inorgânica por meio de Espectroscopia Raman Confocal (ERC)}

Os dentes foram submetidos à análise da composição orgânica e inorgânica da dentina radicular antes e após radiação, por meio de Espectroscopia Raman Confocal (ERC) (Skin Analyzer-model 3510, River Diagnosis BV, Rotterdam, Holanda) (Figura 6). Inicialmente o sistema foi calibrado manualmente, de acordo com as instruções do fabricante. As amostras foram posicionadas com a face a ser analisada voltada para baixo. Uma objetiva de 40x (Olympus) foi então utilizada para concentrar luz gerada pela fonte de laser com comprimento de onda de $785 \mathrm{~nm}$, compreendendo a faixa espectral de $\left(400-1800 \mathrm{~cm}^{-1}\right)$ na região de baixa frequência, com resolução espacial de $2 \mu \mathrm{m}$. A potência do laser foi de $21 \mathrm{~mW}$ e o tempo de exposição de 5 segundos, gerando o espectro. 


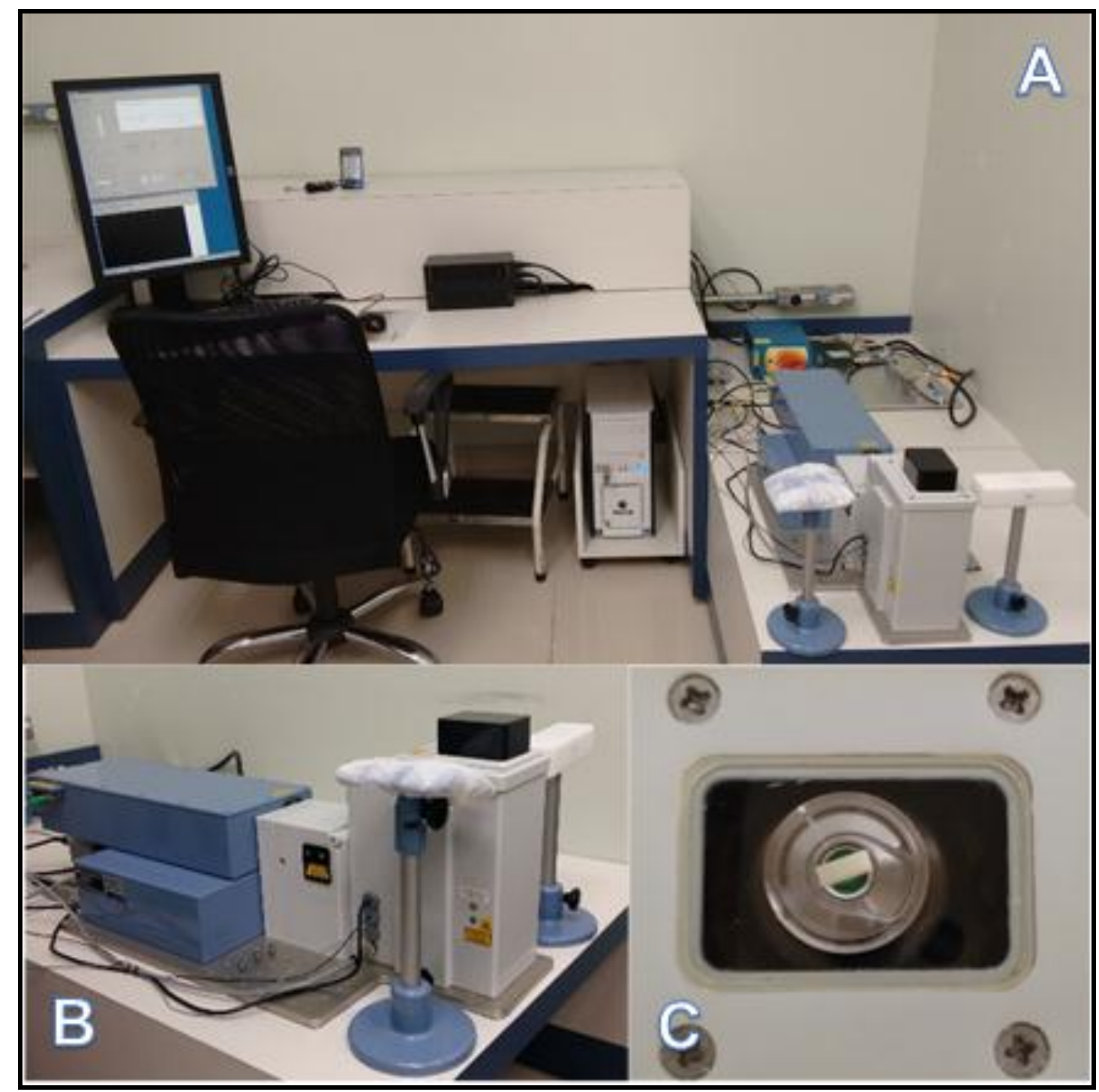

Figura 6. (A) Laboratório de Espectroscopia Raman Confocal com o equipamento acoplado ao software onde são obtidos os espectros Raman. (B) ERC (Rivers Diagnostics -Modelo 3510). (C) Espécime posicionado para análise.

Foram analisadas três regiões: a região da dentina radicular intracanal, de onde foram obtidos três espectros, um de cada terço radicular; a região da dentina radicular média, de onde foram obtidos nove espectros, sendo três de cada terço radicular; e a região de cemento, de onde foram obtidos três espectros, um de cada terço radicular (Figura 7). 


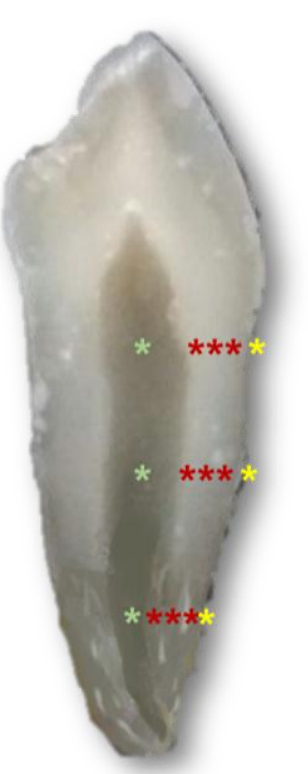

Figura 7. Localização dos espectros obtidos em Espectroscopia Raman Confocal. Pontos verdes - região da dentina radicular intracanal; Pontos vermelhos - região da dentina radicular média; Pontos amarelos - região de superfície radicular externa.

A intensidade dos picos fosfato $-\mathrm{PO}_{4}{ }^{3-}\left(590 \mathrm{~cm}^{-1}\right)$ e carbonato $-\mathrm{CO}_{3}{ }^{2-}(1070$ $\mathrm{cm}^{-1}$ ) no espectro de Raman são proporcionais à quantidade de conteúdo inorgânico enquanto a amida I $\left(1670 \mathrm{~cm}^{-1}\right)$, II $\left(1453 \mathrm{~cm}^{-1}\right)$ e III $\left(1267 \mathrm{~cm}^{-1}\right)$ são proporcionais ao conteúdo orgânico (DE SANT'ANNA et al., 2009; DE SÁ FERREIRA et al., 2016; LOPES, 2016). Uma vez obtidos os espectros, realizou-se a normalização e o cálculo da área dos picos utilizando o programa Microcal Origin 6 (Microcal Origin Software, MA 01060, Northampton, EUA). A figura 8 representa um espectro típico.

Após a obtenção dos dados de área referente a cada pico, a média dos valores encontrados para os componentes químicos avaliados (carbonato, fosfato e amidas I, II e III) em cada região (dentina radicular intracanal, dentina radicular média e cemento), foi calculada. Em seguida, obtiveram-se as médias individuais dos grupos I (ausência de regime radioterápico) e II (regime radioterápico), para posterior análise estatística. 


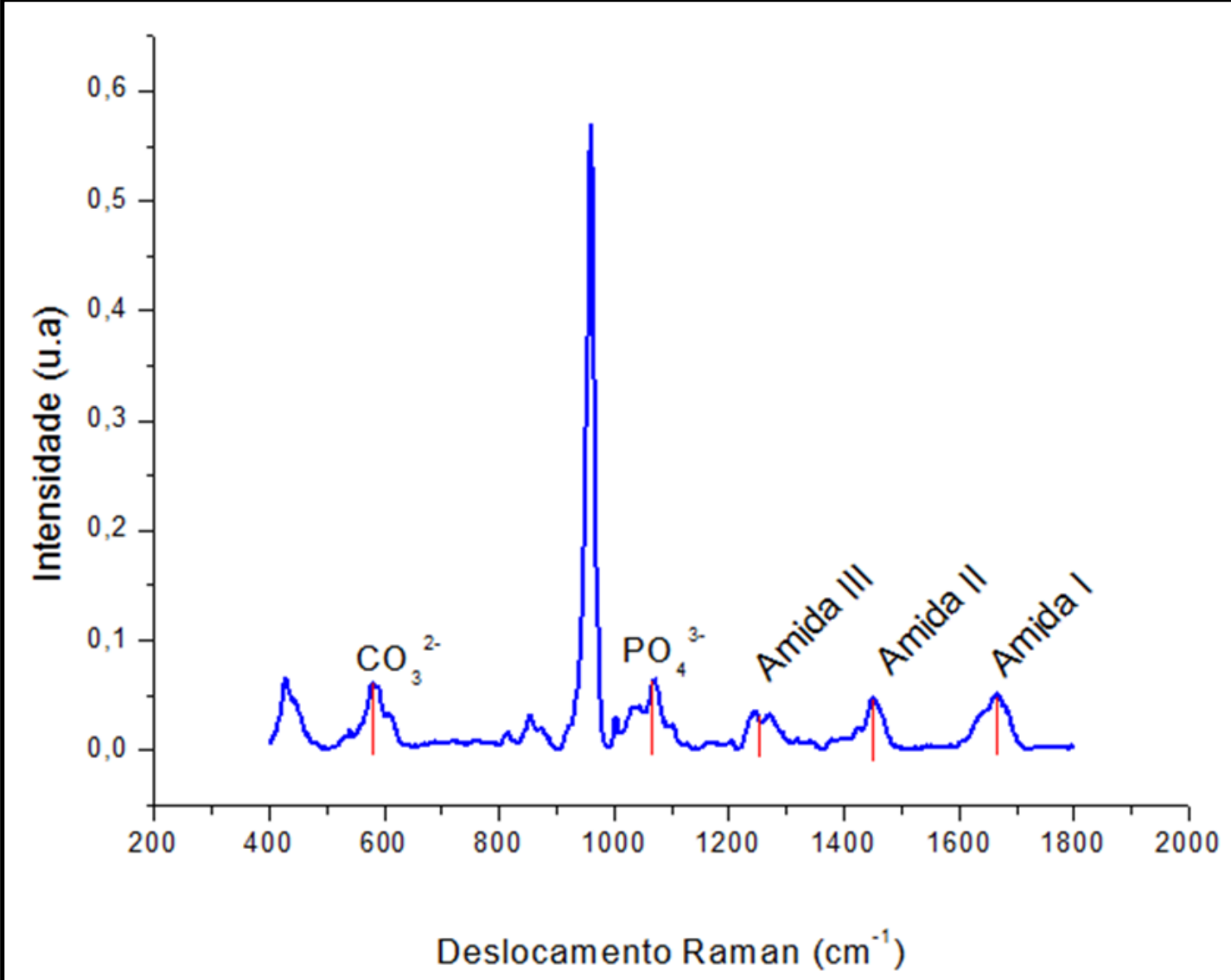

Figura 8. Espectro Raman típico da dentina radicular - pico $\mathrm{CO}_{3}{ }^{2-}$ (carbonato) e $\mathrm{PO}_{4}{ }^{3-}$ (fosfato) referentes ao conteúdo mineral e picos de amida I, II e III referentes ao colágeno.

\section{Análise estatística}

Os dados de fosfato, carbonato e amidas I, II e III foram submetidos inicialmente aos testes de normalidade (Shapiro-Wilk) e homogeneidade de variância (Levene). Uma vez que se constatou distribuição amostral normal e homogênea, os dados foram submetidos ao teste $T$ para amostras independentes avaliando-se a influência da radioterapia nos valores de fosfato, carbonato e amidas I, II e III. Todas as análises foram realizadas no software SPSS v.17.0 for Windows (SPSS Inc, Chicago, IL, EUA) com um nível de probabilidade de $95 \%(\alpha=0,05)$. 



\section{Resultados}

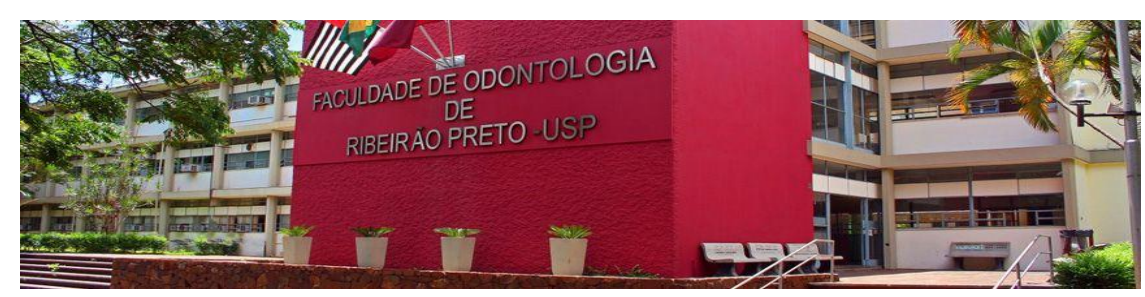





\section{Avaliação do conteúdo inorgânico e orgânico - Dentina radicular intracanal}

Os dados (média \pm desvio padrão) relativos à avaliação da quantidade de fosfato, carbonato e amidas I, II e III observados por meio da microscopia RAMAN na dentina radicular intracanal estão dispostos na Tabela 1. O teste T para amostras independentes evidenciou que o grupo irradiado apresentou menores valores de fosfato quando comparado ao grupo não irradiado $(p=0,021)$. Já para os valores de carbonato, foi observado que os dentes irradiados apresentaram menores valores comparado ao grupo não irradiado $(p=0,003)$. Em relação aos valores de amida, não foi observada diferença estatística entre os grupos em amida I $(p=0,295)$ e amida II $(p=0,792)$. No entanto, o tratamento radioterápico reduziu significativamente os valores de amida III $(p=0,043)$.

Tabela 1. Médias e desvio padrão da intensidade dos picos de fosfato, carbonato e amidas I, II e III na dentina radicular intracanal observado por Espectroscopia Raman Confocal (u.a.).

\begin{tabular}{ccc}
\hline Pico & Não Irradiado & Irradiado \\
\hline Fosfato & $1,40 \pm 0,18 \mathrm{~A}$ & $1,23 \pm 0,06 \mathrm{~B}$ \\
Carbonato & $1,56 \pm 0,06 \mathrm{~B}$ & $1,42 \pm 0,10 \mathrm{~A}$ \\
Amida I & $1,66 \pm 0,11 \mathrm{~A}$ & $1,73 \pm 0,16 \mathrm{~A}$ \\
Amida II & $1,77 \pm 0,25 \mathrm{~A}$ & $1,79 \pm 0,15 \mathrm{~A}$ \\
Amida III & $1,28 \pm 0,24 \mathrm{~A}$ & $1,05 \pm 0,19 \mathrm{~B}$ \\
\hline
\end{tabular}

*letras diferentes indicam diferença estatística entre os tratamentos irradiado e não irradiado.

\section{Avaliação do conteúdo inorgânico e orgânico - Dentina radicular média}

Os dados (média \pm desvio padrão) relativos à avaliação da quantidade de fosfato, carbonato e amidas I, II e III observados por meio da microscopia RAMAN na dentina radicular média estão dispostos na Tabela 2. O teste $\mathrm{T}$ para amostras independentes evidenciou que o grupo irradiado apresentou menores valores de fosfato quando comparado ao grupo não irradiado $(p=0,050)$. Em relação aos 
valores de carbonato $(p=0,859)$, amida I $(0,785)$, amida II $(p=0,771)$ e amida III $(p=0,338)$ não foi observada diferença estatística entre dentes irradiados e não irradiados.

Tabela 2. Médias e desvio padrão da intensidade dos picos de fosfato, carbonato e amidas I, II e III na dentina radicular média observado por Espectroscopia Raman Confocal (u.a.).

\begin{tabular}{ccc}
\hline Pico & Não Irradiado & Irradiado \\
\hline Fosfato & $1,48 \pm 0,22 \mathrm{~A}$ & $1,30 \pm 0,12 \mathrm{~B}$ \\
Carbonato & $1,45_{ \pm} 0,12 \mathrm{~A}$ & $1,44_{ \pm} 0,06 \mathrm{~A}$ \\
Amida I & $1,80 \pm 0,15 \mathrm{~A}$ & $1,78_{ \pm} 0,17 \mathrm{~A}$ \\
Amida II & $1,81 \pm 0,22 \mathrm{~A}$ & $1,75_{ \pm} 0,09 \mathrm{~A}$ \\
Amida III & $1,16 \pm 0,13 \mathrm{~A}$ & $1,14 \pm 0,11 \mathrm{~A}$ \\
\hline
\end{tabular}

*letras diferentes indicam diferença estatística entre os tratamentos irradiado e não irradiado.

\section{Avaliação do conteúdo inorgânico e orgânico - Cemento}

Os dados (média \pm desvio padrão) relativos à avaliação da quantidade de fosfato, carbonato e amidas I, II e III observados por meio da microscopia RAMAN em cemento estão dispostos na Tabela 3. O teste T para amostras independentes evidenciou que não houve diferença estatística entre os grupos irradiado e não irradiado para os valores de fosfato $(p=0,448)$, carbonato $(p=0,575)$ e amida I $(p=0,225)$, amida II $(p=0,437)$ e amida III $(p=0,187)$.

Tabela 3. Médias e desvio padrão da intensidade dos picos de fosfato, carbonato e amidas I, II e III em cemento observado por Espectroscopia Raman Confocal (u.a.)

\begin{tabular}{ccc}
\hline Pico & Não Irradiado & Irradiado \\
\hline Fosfato & $1,45 \pm 0,24 \mathrm{~A}$ & $1,53 \pm 0,19 \mathrm{~A}$ \\
Carbonato & $1,38_{ \pm 0}, 14 \mathrm{~A}$ & $1,33_{ \pm 0,17 \mathrm{~A}}$ \\
Amida I & $2,08 \pm 0,19 \mathrm{~A}$ & $1,89 \pm 0,39 \mathrm{~A}$ \\
Amida II & $1,89 \pm 0,14 \mathrm{~A}$ & $1,79 \pm 0,32 \mathrm{~A}$ \\
Amida III & $1,23 \pm 0,15 \mathrm{~A}$ & $1,09 \pm 0,25 \mathrm{~A}$ \\
\hline
\end{tabular}

*letras diferentes indicam diferença estatística entre os tratamentos irradiado e não irradiado. 

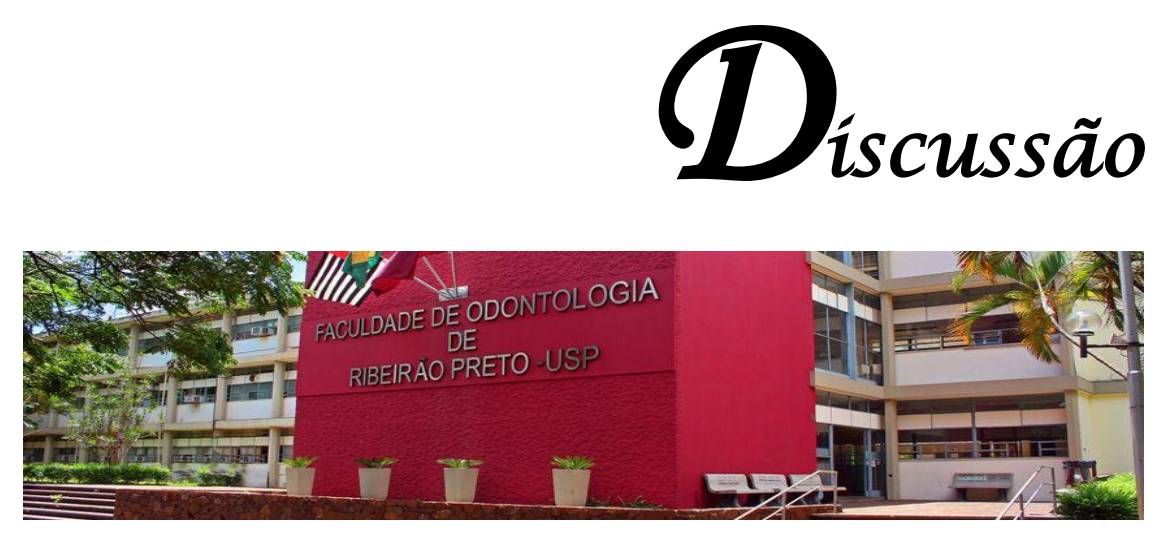

A radioterapia utilizada no tratamento do câncer de cabeça e pescoço, é direcionada à massa tumoral (ADELSTEIN, 2003; CHAACHOUAY et al., 2011; GONÇALVES et al., 2014; MARTINS et al., 2016), entretanto, nem sempre é possível preservar os tecidos circunvizinhos (THIAGARAJAN; IYER, 2014; KHAN et al., 2016; ROŚ-MAZURCZYK et al., 2016) ocasionando efeitos colaterais na cavidade bucal (LARSON et al., 1983; JACOBSSON et al., 1985; TOMITA; OSAKI, 1990; FRANZEN et al., 1995; KIELBASSA et al., 1997; HOLLINGSWORTH et al., 2016), entre eles alterações químicas na estrutura dental (DE SIQUEIRA MELLARA et al., 2014; GONÇALVES et al., 2014; QING et al., 2015; DE SÁ FERREIRA et al., 2016).

As alterações químicas nos compostos inorgânicos bem como na estrutura de colágeno dental, que apresenta em sua composição amidas I, II e III (GELSE; POSCHL; AIGNER, 2003; RODRIGUES, 2015; DE SÁ FERREIRA et al., 2016; LOPES et al., 2016) podem impactar diretamente na qualidade dos procedimentos restauradores (SOARES et al., 2010; DE SIQUEIRA MELLARA et al., 2014; ARID, 2015; SANTIN et al., 2015; DE SIQUEIRA MELLARA, 2016; MARTINS et al., 2016). Destaca-se que a incidência e a prevalência desses efeitos adversos dependem da quantidade e frequência da dose de radiação dispensada (OHRN; WAHLIN; SJÖDÉN, 2001; DE SIQUEIRA MELLARA, 2016).

Em relação à metodologia empregada neste estudo, foi utilizado o fracionamento convencional, com doses de 2 Gy, por 5 dias consecutivos, com 30 ciclos, durante 6 semanas, perfazendo o total de 60 Gy (KIELBASSA, 2000; AÇIL et al., 2007; AGGARWAL, 2009; BULUCU et al., 2009; SOARES et al., 2010; SOARES; NEIVA; SOARES, 2011; DE SIQUEIRA MELLARA et al., 2014; GONÇALVES et al., 2014; ARID, 2015; MARTINS et al., 2016), para simular as 
condições clínicas no tratamento de pacientes oncológicos (GONÇALVES et al., 2014; MARTINS et al., 2016), com uso do acelerador linear, que é um aparelho preciso para a radioterapia de pacientes com câncer de cabeça e pescoço, irradiando estruturas neoplásicas com maior precisão quanto a localização e intensidade do feixe (ARID, 2015; SANTIN et al., 2015; DE SIQUEIRA MELLARA, 2016; MARTINS et al., 2016).

Os dentes foram armazenados em saliva artificial composta de fosfato, diácido de potássio, fosfato dibásico de potássio, cloreto de potássio, cloreto de sódio, cloreto de magnésio, cloreto de cálcio, fluoreto de sódio, sorbitol $70 \%$, aromatizante, conservantes (nipagin/nipasol), espessante e água (GONÇALVES et al., 2014; MARTINS et al., 2016). Entretanto, apesar de não reproduzir exatamente as características da saliva natural, principalmente nos casos de pacientes irradiados com alterações de fluxo e composição salivar, a saliva artificial ainda é a opção que mais se assemelha às condições clínicas da saliva natural (AMAECHI; HIGHAM, 2001; GONÇALVES et al., 2014; MARTINS et al., 2016). A literatura evidencia o uso de diferentes soluções no armazenamento dos corpos de prova, tais como água destilada (JANSMA et al., 1988; SOARES et al., 2010), solução fosfatada tamponada (PIOCH; GOLFELS; STAEHLE, 1992), solução salina a 0,9\% (JANSMA et al., 1990; KIELBASSA et al., 1997; AL-NAWAS et al., 2000; KIELBASSA, 2000), e saliva artificial (SOARES; NEIVA; SOARES, 2011; DE SIQUEIRA MELLARA et al., 2014).

Destaca-se que durante a exposição à irradiação gama os dentes foram imersos em água destilada, uma vez que a imersão em saliva artificial poderia dificultar a distribuição homogênea da irradiação, devido à sua viscosidade e alta concentração de íons (ARID, 2015; SANTIN et al., 2015; MARTINS et al., 2016). 
Além disso, a água é o principal constituinte dos tecidos humanos e, dessa forma a imersão em água destilada durante a radioterapia pode simular os tecidos moles circundantes tanto do ponto de vista físico como químico pela formação de radicais livres (ARID, 2015; SANTIN et al., 2015; MARTINS et al., 2016).

Os dentes com restaurações metálicas foram excluídos da amostra, uma vez que em contato com a irradiação as restaurações podem aumentar a quantidade de radiação secundária (GALETTI et al., 2014; MARTINS et al., 2016), o que tornaria complexo o controle das variáveis e a padronização dos resultados (SPECHT; KIRKEGAARD, 2002; BEKES et al., 2009; WALKER et al., 2011). Ainda, com o intuito de aumentar a confiabilidade dos resultados obtidos, foram selecionados dentes homólogos devido à coincidência na época de formação e semelhanças de desenvolvimento estrutural (CAMPOS; CRUZ; MELLO, 2004).

Para o estudo das alterações químicas na estrutura dental provocadas pela radioterapia, foi utilizado a Espectroscopia Raman Confocal que possibilita a identificação de ligações químicas características de compostos orgânicos e inorgânicos através de mudança de polaridade associada a modos vibracionais das moléculas, como os grupos $\mathrm{O}-\mathrm{H}, \mathrm{N}-\mathrm{H}, \mathrm{C}=\mathrm{O}, \mathrm{C}-\mathrm{N}, \mathrm{C}-\mathrm{O}$, de forma não destrutiva e altamente precisa (LEUNG; MORRIS, 1995; SALA, 1995; TSUDA; ARENDS, 1997; AKKUS et al., 2003; LIU; HSU, 2007; SOARES et al., 2009; PASCON et al., 2012), permitindo a análise da intensidade dos picos de fosfato, carbonato e amidas I, II e III (LEUNG; MORRIS, 1995; SALA, 1995; TSUDA; ARENDS, 1997; AKKUS et al., 2003; LIU; HSU, 2007; DE SANT'ANNA et al., 2009; SOARES et al., 2009; PASCON et al., 2012; AKKUS et al., 2016; DE SÁ FERREIRA et al., 2016; LOPES, et al. 2016). 
Os resultados obtidos por meio do teste $\mathrm{T}$ para amostras independentes evidenciaram que na região de dentina radicular intracanal, bem como na região de dentina radicular média, o grupo irradiado apresentou menores valores de fosfato, provavelmente em função da presença da molécula de fósforo na estrutura da hidroxiapatita estar localizada mais externamente, o que a torna mais instável e suscetível a danos (OLIVEIRA, 2007; DE SÁ FERREIRA et al., 2016). A banda de fosfato $\left(590 \mathrm{~cm}^{-1}\right)$ representa a energia vibracional associada a ligação entre 0 fosfato e o oxigênio na molécula de hidroxiapatita (JONES; BOYDE, 1984; RODRIGUES, 2015; DE SÁ FERREIRA et al., 2016). De forma semelhante, GONÇALVES et al. (2014), ao quantificarem o conteúdo mineral da dentina coronária de dentes permanentes antes e após 60 Gy de irradiação, por meio da espectroscopia de energia dispersiva de raios $X$ (EDX), verificaram diminuição na porcentagem de fósforo.

Já para os valores de carbonato, foi observado que os dentes irradiados apresentaram menores valores quando comparado ao grupo não irradiado na região de dentina radicular intracanal, devido a um desequilíbrio nas trocas iônicas que ocorrem entre fosfato e carbonato (FEAGIN et al., 1971), tornando a dentina mais solúvel e susceptível à perda de íons para a saliva artificial (GONÇALVES et al., 2014; DE SÁ FERREIRA et al., 2016). Tal desequilíbrio está relacionado ao menor grau de mineralização e maior densidade de túbulos na região da dentina radicular intracanal (CRAIG; GEHRING; PEYTON, 1959; RAUTIOLA; CRAIG, 1961; PASHLEY, 1985; MJÖR; NORDAHL, 1996; TORABINEJAD et al., 2002), o que também justifica a não alteração do carbonato na região de dentina radicular média. Somado a isso, a literatura evidencia a diminuição da microdureza dentinária após a radioterapia (DE SIQUEIRA MELLARA et al., 2014; GONÇALVES et al., 2014; 
NOVAIS et al., 2016), que pode ser explicada pela diminuição do conteúdo inorgânico, observado no presente estudo.

No presente estudo, foi possível observar que os dentes irradiados apresentaram valores reduzidos nos picos de amida III quando comparado ao grupo não irradiado na região da dentina radicular intracanal, o que resulta na desorganização na estrutura secundária da unidade proteica formadora das fibras colágenas (LACERDA; PLEIPIS; GOISSIS, 1998; BET; GOISSIS; LACERDA, 2001), modificando o arranjo natural entre os conteúdos minerais e orgânicos da dentina (SILVESTRIN; ALENCASTRO, 2007; PRESTES et al., 2013), o que provavelmente pode justificar as mudanças nas suas propriedades mecânicas tais como: aumento da solubilidade (KNOTT; BAILEY, 1998; DZIEDZIC-GOCLAWSKA et al., 2005; KOCHUEVA; IGNATIEVA; ZAKHARKINA, 2012), diminuição da resistência à tração da dentina coronária e radicular (SOARES et al., 2010), bem como a ocorrência de fraturas por cisalhamento (WALKER et al., 2011).

Por outro lado, não foi observada diferença estatística entre os dentes irradiados e não irradiados para os valores de amida I e II, demonstrando que a radioterapia não leva à perda efetiva em quantidade do conteúdo orgânico (OLIVEIRA et al., 2012; BANHARA, 2016), no entanto causa alterações morfológicas e estruturais no colágeno evidenciado pela redução dos picos de amida III. Os modos vibracionais característicos da amida I são estiramentos entre $\mathrm{C}=\mathrm{O}$, com menor contribuição de deformação de $\mathrm{N}-\mathrm{H}$ (CHOI; $\mathrm{CHO}, 2009)$, enquanto que amida II está relacionado à deformação angular de N-H e estiramento da ligação CN (OLIVEIRA et al., 2012; BANHARA, 2016).

Na região cementária, não foi observada diferença estatística entre os grupos irradiado e não irradiado para os valores de fosfato, carbonato e amida I, amida II e 
amida III. Os resultados encontrados para o cemento diferem da dentina possivelmente devido às diferenças estruturais dos tecidos (SASAKI et al., 2002), como o menor grau de mineralização e a maior quantidade de substância orgânica do cemento (MJÖR; FEJERSKOV, 1991).

As alterações químicas na estrutura de colágeno após a radioterapia, evidenciadas pela alteração nos picos de amida III, podem interferir diretamente na resistência de união dos materiais adesivos, interferindo no prognóstico dos tratamentos restauradores (KIELBASSA et al., 1997; GRÖTZ et al., 1997; ALNAWAS et al., 2000; SPRINGER et al., 2005; AÇIL et al., 2007; SOARES et al., 2010; SOARES; NEIVA; SOARES, 2011; GONÇALVES et al., 2014; DE SIQUEIRA MELLARA et al., 2014; CARPIO-BONILLA, 2016; DE SÁ FERREIRA et al., 2016; MARTINS et al., 2016). Assim, torna-se necessário estabelecer protocolos para prevenir ou atenuar os efeitos deletérios durante o tratamento radioterápico, bem como propor materiais e técnicas mais adequados que promovam 0 restabelecimento estético e funcional destes pacientes. 


\section{Conclusões}

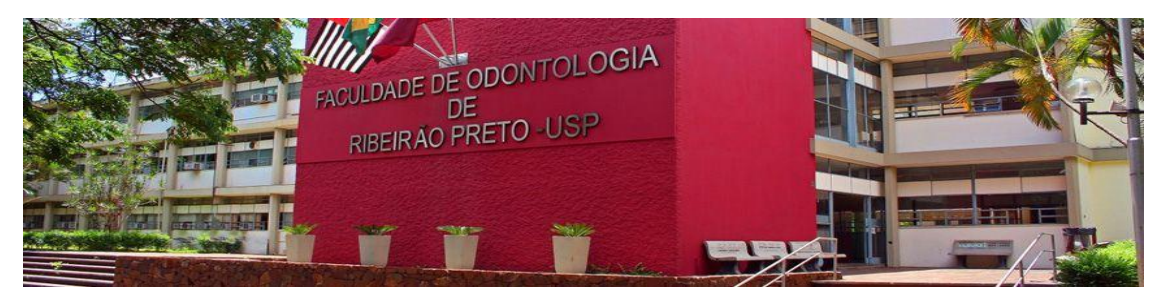



Diante da metodologia empregada e com base nos resultados obtidos, é licito concluir que:

1- A radioterapia foi capaz de provocar alterações no conteúdo inorgânico (fosfato e carbonato) e em colágeno (amida III) da dentina radicular intracanal;

2- A radioterapia foi capaz de provocar alterações apenas no conteúdo inorgânico (fosfato) da dentina radicular média;

3- A radioterapia não provocou alterações químicas em cemento. 



\section{$\mathbb{R}_{\text {eferencias }} \boldsymbol{B}_{\text {ibliográficas }}$}

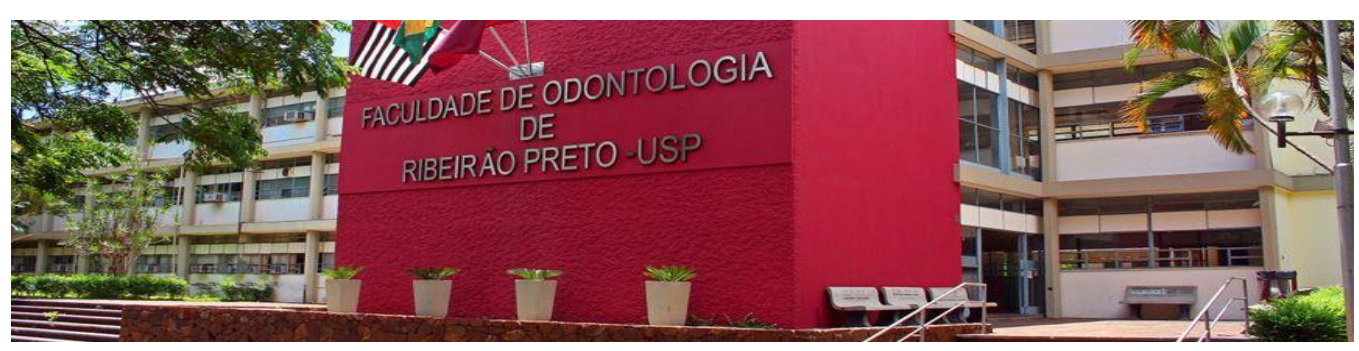



AÇIL, Y.; SPRINGER, I. N.; NIEHOFF, P.; GAßLING, V.; WARNKE, P. H.; AÇMAZ, S.; SÖNMEZ, T. T.; KIMMIG, B.; LEFTERIS, V.; WILTFANG, J. Proof of Direct Radiogenic Destruction of Collagen in Vitro. Strahlentherapie Onkologie, n. 7, 2007.

ADELSTEIN, D. J. Systemic chemotherapy for squamous cell head and neck cancer. Expert Opinion on Pharmacotherapy, v. 4, n. 12, p. 2151-2163, 2003.

AGARWAL, P.; SHIVA KUMAR, H. R.; RAI, K. K. Trismus in oral cancer patients undergoing surgery and radiotherapy. Journal of Oral Biology and Craniofacial Research, v. 1, p. S9-S13, 2016.

AGGARWAL, V. An in vitro evaluation of effect of ionizing radiotherapy on push-out strength of fiber posts under cyclic loading. Journal of Endodontics, v. 35, n. 5, p. 695-8, 2009.

AKKUS, A.; AKKUS, A.; ROPERTO, R.; AKKUS, O.; PORTO, T.; TEICH, S.; LANG, L. Evaluation of mineral content in healthy permanent human enamel by Raman spectroscopy. Journal of Clinical and Experimental Dentistry, v. 8, n. 5, p. e546e549, 2016.

AKKUS, O.; POLYAKOVA-AKKUS, A.; ADAR, F.; SCHAFFLER, M. B. Aging of microstructural compartments in human compact bone. Journal of Bone and Mineral Research, v. 18, n. 6, p. 1012-9, 2003.

AL-NAWAS, B.; GRÖTZ, K. A.; ROSE, E.; DUSCHNER, H.; KANN, P.; WAGNER, W. Using ultrasound transmission velocity to analyse the mechanical properties of teeth after in vitro, in situ, and in vivo irradiation. Clinical Oral Investigation, v. 4, p. 168-172, 2000.

AMAECHI, B. T.; HIGHAM, S. M. In vitro remineralisation of eroded enamel lesions by saliva. Journal of Dentistry, v. 29, n. 5, p. 371-376, 2001.

ANGKER, L.; NIJHOF, N.; SWAIN, M. V.; KILPATRICK, N. M. Influence of hydration and mechanical characterization of carious primary dentine using an ultra-micro 
indentation system (UMIS). European Journal of Oral Sciences, v. 112, p. 231236, 2004.

ARID, J. Efeito da Radioterapia na Adesão e Interface ao Substrato de Dentes Permanentes. Ribeirão Preto: Dissertação de Mestrado [Faculdade de Odontologia de Ribeirão Preto - Universidade de São Paulo], p. 98, 2015.

BANHARA, V. F. Análise das alterações biomoleculares causadas pelo fármaco Diclofenaco Sódico em peixes da espécie Brycon opalinus através da espectroscopia no infravermelho por ransformada de fourier (FTIR). São José dos Campos: Dissertação de Mestrado [Universidade do Vale do Paraíba], 2016.

BEECH, N.; ROBINSON, S.; PORCEDDU, S.; BATSTONE, M. Dental management of patients irradiated for head and neck cancer. Australian Dental Journal, v. 59, n. 1, p. 20-8, 2014.

BEKES, K.; FRANCKE, U.; SCHALLER, H.; KUHNT, T.; GERLACH, R.; VORDERMARK, B.; GERNHARDT, C. R. The influence of different irradiation doses and desensitizer application on demineralization of human dentin. Oral Oncology, v. 45 , p. 80-84, 2009.

BESSELL, A.; GLENNY, A. M.; FURNESS, S.; CLARKSON, J. E.; OLIVER, R.; CONWAY, D. I.; MACLUSKEY, M.; PAVITT, S.; SLOAN, P.; WORTHINGTON, H. V. Interventions for the treatment of oral and oropharyngeal cancers: surgical treatment. Cochrane Database of Systematic Reviews, v.7, n.9, 2011.

BET, M. R.; GOISSIS, G.; LACERDA, C. A. Characterization of Polyanionic collagen prepared by selective hydrolysis of asparagine and glutamine caboxyamide side chains. Biomacromolecules, v. 2, p. 1074-1079, 2001.

BEUMER, J.; CURTIS, T. A.; MARUNICK, M. T. Maxillofacial rehabilitation: prosthodontic and surgical considerations. Ishiyaku EuroAmerica, 1996. 
BULUCU, B.; AVSAR, A.; DEMIRYÜREK, E. O.; YESILYURT, C. Effect of radiotherapy on the microleakage of adhesive systems. Journal of Adhesive Dentistry, v. 11, n. 4, p. 305-309, 2009.

CAMPOS, V.; CRUZ, R. A.; MELLO, H. S. A. Diagnóstico e Tratamento das Anomalias da Odontogênese. São Paulo: Santos, ed. 1, p. 83, 2004.

CARPIO-BONILLA, C. M. Radioterapia ativa e inibidores de proteases inativam MMPs, na junção amelodentinária de dentes permanentes. Ribeirão Preto: Dissertação de Mestrado [Faculdade de Odontologia de Ribeirão Preto Universidade de São Paulo], 2016.

CARRARA-COTOMACIO, C.; CAMPOS, L.; SIMÕES, A.; CHAGAS-JAGUAR, G.; CROSATO, E. M.; ABREU-ALVES, F. Influence of bethanechol on salivary parameters in irradiated patients. Medicina Oral, Patología Oral y Cirugía Bucal, v. 22, n. 1, p. e76-e83, 2017.

CHAACHOUAY, H.; OHNESEIT, P.; TOULANY, M.; KEHLBACH, R.; MULTHOFF, G.; RODEMANN, H. P. Autophagy contributes to resistance of tumor cells to ionizing radiation. Radiotherapy and Oncology, v. 99, n. 3, p. 287-92, 2011.

$\mathrm{CHOI}, \mathrm{J} . \mathrm{H}$; $\mathrm{CHO}$, M. Calculations of intermode coupling constants and simulations of amide I, II, III vibrational spectra of dipeptides. The Journal of Chemical Physics, v. 361 , n. 3, p. 168-175, 2009.

COLOMBO, J.; RAHAL, P. Alterações genéticas em câncer de cabeça e pescoço. Revista Brasileira de Cancerologia, v. 55, n. 2, p. 165-74, 2009.

CRAIG, R. G.; GEHRING, P. E.; PEYTON F. A. Relation of estructure to the microhardness of human dentine. Journal of Dental Research, v. 38, n. 3, p. 62430, 1959.

DA SILVA, F. T; PENNA, A. L. B. Colágeno: Características químicas e propriedades funcionais. Revista do Instituto Adolfo Lutz, v. 71, n. 3, p. 530-539, 2012. 
DE MElO COStA, A. C. F.; DE LIMA, M. G.; DE ALMEIDA LiMA, L. H. M.; CORDEIRO, V. V.; DE SOUTO VIANA, K. M.; DE SOUZA, C. V.; DE LUCENA LIRA, H. Hidroxiapatita: Obtenção, caracterização e aplicações. Revista eletrônica de Materiais e Processos, v. 4, n. 3, 2009.

DE SÁ FERREIRA, E. M.; SOARES, L. E.; ANTUNES, H. S.; UEMURA, S.T.; DA SILVA BARBOSA, P.; SALMON, H. A. J. R.; DE SANT'ANNA, G.R. Effect of therapeutic doses of radiotherapy on the organic and inorganic contents of the deciduous enamel: an in vitro study. Clinical Oral Investigations, 2016.

DE SANT'ANNA, G. R.; DOS SANTOS, E. A.; SOARES, L. E.; DO ESPÍRITO SANTO, A. M.; MARTIN, A. A.; DUARTE, D. A.; PACHECO-SOARES, C., BRUGNERA, A. JR. Dental enamel irradiated with infrared diode laser and photoabsorbing cream: part 2--EDX study. Photomedicine and Laser Surgery, v. 27, n. 5, p. 771-82, 2009.

DE SIQUEIRA MELLARA, T. Adesão de diferentes sistemas adesivos ao esmalte e à dentina de dentes decíduos submetidos à radioterapia. Ribeirão Preto: Tese de Doutorado [Faculdade de Odontologia de Ribeirão Preto - Universidade de São Paulo], p. 118, 2016.

DE SIQUEIRA MELLARA, T.; PALMA-DIBB, R. G.; DE OLIVEIRA, H. F.; PAULASILVA, F. W. G.; NELSON-FILHO, P.; DA SILVA, R. A. B.; DE QUEIROZ, A. M. The effect of radiation therapy on the mechanical and morphological properties of the enamel and dentin of deciduous teeth-an in vitro study. Radiation Oncology, v. 9, n. 1, p. 1, 2014.

DOBROŚ, K.; HAJTO-BRYK, J.; WRÓBLEWSKA, M.; ZARZECKA, J. Radiationinduced caries as the late effect of radiation therapy in the head and neck region. Contemporary Oncology, v. 20, n. 4, p. 287-290, 2016.

DZIEDZIC-GOCLAWSKA, A.; KAMINSKI, A.; UHRYNOWSKA-TYSZKIEWICZ, I.; STACHOWICZ, W. Irradiation as a safety procedure in tissue banking. Cell and Tissue Banking, v. 6, n. 3, p. 201-219, 2005. 
FEAGIN, F.; PATEL, P. R.; KOULOURIDES, T.; PIGMAN, W. Study of the effect of calcium, phosphate, fluoride and hydrogen ion concentrations on the remineralization of partially demineralized human and bovine enamel surfaces. Archives of Oral Biology, v. 16, n. 5, p. 535-48, 1971.

FERGUSON, H. W.; STEVENS, M. R. Advances in head and neck radiotherapy to the mandible. Oral and maxillofacial surgery clinics of North America, v. 19, n. 4, p. 553-563, 2007.

FLETCHER, G. H. Regaud lecture perspectives on the history of radiotherapy. Radiotherapy and Oncology, v. 12, n. 4, p. 253-271, 1988.

FRANZEN, L.; HENRIKSSON, R.; LITTBRAND, B.; ZACKRISSON, B. Effects of sucralfate on mucositis during and following radiotherapy of malignancies in the head and neck region. A double-blind placebo-controlled study. Acta Oncológica, v. 34, n. 2, p. 219-223, 1995.

GALETTI, R.; SANTOS-SILVA, A. R.; ANTUNES, A. N.; ALVES FDE, A.; LOPES, M. A.; DE GOES, M. F. Radiotherapy does not impair dentin adhesive properties in head and neck cancer patients. Clinical Oral Investigations, v. 18, n. 7, p. 1771-8, 2014.

GAUDET, M. M.; KITAHARA, C. M.; NEWTON, C. C.; BERNSTEIN, L.; REYNOLDS, P.; WEIDERPASS, E.; KREIMER, A. R.; YANG, G.; ADAMI, H. O.; ALAVANJA, M. C.; BEANE FREEMAN, L. E.; BOEING, H.; BURING, J.; CHATURVEDI, A.; CHEN, Y.; D'AlOISIO, A. A.; FREEDMAN, M.; GAO, Y. T.; GAZIANO, J. M.; GILES, G. G.; HÅKANSSON, N.; HUANG, W. Y.; LEE, I. M.; LINET, M. S.; MACINNIS, R. J.; PARK, Y.; PRIZMENT, A.; PURDUE, M. P.; RIBOLI, E.; ROBIEN, K.; SANDLER, D. P.; SCHAIRER, C.; SESSO, H. D.; OU SHU, X.; WHITE, E.; WOLK, A.; XIANG, Y. B.; ZELENUICH-JACQUOTTE, A.; ZHENG, W.; PATEL, A. V.; HARTGE, P.; BERRINGTON DE GONZÁLEZ, A.; GAPSTUR, S. M. Anthropometry and head and neck cancer: a pooled analysis of cohort data. International Journal of Epidemiology, v. 44, n. 2, p. 673-81, 2015. 
GELSE, K.; POSCHL, E.; AIGNER, T. Collagens-structure, function, and biosynthesis. Advanced Drug Delivery Reviews, v. 55, p.1531-1546, 2003.

GLOBOCAN - International Agency for Cancer Research. Disponível em: http://globocan.iarc.fr/Default.aspx (Acessado em 29/12/2016).

GONÇALVES, L. M. N.; PALMA-DIBB, R. G.; PAULA-SILVA, F. W. G., DE OLIVEIRA, H. F.; NELSON-FILHO, P.; DA SILVA, L. A. B.; DE QUEIROZ, A. M. Radiation therapy alters microhardness and microstructure of enamel and dentin of permanent human teeth. Journal of dentistry, v. 42, n. 8, p. 986-992, 2014.

GRÖTZ, K. A.; DUSCHNER, H.; KUTZNER, J.; THELEN, M.; WAGNER, W. New evidence for the etiology of so-called radiation caries. Proof for directed radiogenic damage on the enamel-dentin junction. Strahlentherapie und Onkologie: Organ der Deutschen Rontgengesellschaft, v. 173, n. 12, p. 668-676, 1997.

GUPTA, N.; PAL, M.; RAWAT, S.; GREWAL, M. S.; GARG, H.; CHAUHAN, D.; AHLAWAT, P.; TANDON, S.; KHURANA, R.; PAHUJA, A. K.; MAYANK, M.; DEVNANI, B. Radiation-induced dental caries, prevention and treatment - A systematic review. National Journal of Maxillofacial Surgery. V. 6, n. 2,p. 160-6, 2015.

GUY POYTO, H. P. M. Oral radiology. BC Decker, p.17-19, 1989.

HOLLINGSWORTH, B.; SENTER, L.; ZHANG, X.; BROCK, G. N.; JARJOUR, W.; NAGY, R.; BROCK, P.; COOMBES, K. R.; KLOOS, R. T.; RINGEL, M. D.; SIPOS, J.; LATTIMER, I.; CARRAU, R.; JHIANG S. M. Risk Factors of 131IInduced Salivary Gland Damage in Thyroid Cancer Patients. Journal of Clinical Endocrinology and Metabolism, v. 101, n. 11, 2016.

INCA - Instituto Nacional do Câncer. Controle do Câncer: uma proposta de integração ensino-serviço. Pro-Onco, ed. 2, 1993. Disponível em: http://www2.inca.gov.br/wps/wcm/connect/sobreinca/site/oinstituto (Acessado em 29/12/2016). 
INCA - Instituto Nacional do Câncer. Disponível em: http//www2.inca.gov.br (Acessado em 29/12/2016).

JACOBSSON, M.; JÖNSSON, A.; ALBREKTSSON, T.; TURESSON, I. Doseresponse for bone regeneration after single doses of $60 \mathrm{Co}$ irradiation. International Journal of Radiation Oncology Biology Physics, v. 11, n. 11, p. 1963-1969, 1985.

JAGUAR, G. C.; LIMA, E. N.; KOWALSKI, L. P.; PELLIZZON, A. C.; CARVALHO, A. L.; BOCCALETTI, K. W. Double blind randomized prospective trial of bethanechol in the prevention of radiation-induced salivary gland dysfunction in head and neck cancer patients. Radiotherapy and Oncology, v. 115, n. 2, p.253-256, 2015.

JANSMA, J.; BORGGREVEN, J. M.; DRIESSENS, F. C.; GRAVENMADE, E. J. Effect of X-ray irradiation on the permeability of bovine dental enamel. Caries Research, v. 24, n. 3, p. 164-168, 1990.

JANSMA, J.; BUSKES, J. A. K. M.; VISSINK, A.; MEHTA, D. M. The effect of X-ray irradiation on the demineralization of bovine dental enamel. Caries Research, v. 22, n. 4, p. 199-203, 1988.

JEMAL, A.; SIEGEL, R.; WARD, E.; HAO, Y.; XU. J.; MURRAY, T. Cancer statistics. CA: A Cancer Journal for Clinicians, v.58, n. 71, p. 96, 2008.

JHAM, B. C; FREIRE, A. R. S. Oral complications of radiotherapy in the head and neck. Revista Brasileira de Otorrinolaringologia, v. 72, n. 5, p. 704-708, 2006.

JONES, S. J.; BOYDE, A. Ultrastructure of dentin and dentinogenesis. In: Dentin and dentinogenesis. CRC Press, p.81-134, 1984.

KATAOKA, S. H.; SETZER, F. C.; FREGNANI, E. R.; PESSOA, O. F.; GONDIM, E. J. R.; CALDEIRA, C. L. Effects of 3-dimensional conformal or intensity-modulated radiotherapy on dental pulp sensitivity during and after the treatment of oral or oropharyngeal malignancies. Journal of Endodontics, v. 38, n. 2, p. 148-152, 2012. 
KHAN, S.; FEROZ, S.; JAIN, M.; MATHUR, V.; KHAN S. Effect of Fractionated Dose of Radiotherapy on Oral Mucosa in Head and Neck Cancer Patients: A Cytological Assessment. Gulf Journal of Oncology, v.1, n. 21, p. 30-35, 2016.

KHAW, A.; LOGAN, R.; KEEFE, D.; BARTOLD, M. Radiation-induced oral mucositis and periodontitis-proposal for an inter-relationship. Oral Diseases, v. 20, n. 3, p. e7e18, 2014.

KIELBASSA, A. M. In situ induced demineralization in irradiated and non-irradiated human dentin. European Journal of Oral Sciences, v. 108, n. 3, p. 214-221, 2000.

KIELBASSA, A. M.; BEETZ, I.; SCHENDERA, A.; HELLWIG, E. Irradiation effects on microhardness of fluoridated and non-fluoridated bovine dentin. European Journal of Oral Sciences, v. 105, n. 5P1, p. 444-447, 1997.

KIELBASSA, A. M.; HELLWIG, E.; MEYER-LÜCKEL, H. Effects of irradiation on in situ remineralization of human and bovine enamel demineralised in vitro. Caries Research, v. 40, p. 130-135, 2006.

KIELBASSA, A. M.; MUNZ, I.; BRUGGMOSER, G.; SCHULTE-MÖNTING, J. Effect of demineralization and remineralization on microhardness of irradiated dentin. The Journal of Clinical Dentistry, v. 13, n. 3, p. 104-110, 2002.

KIELBASSA, A. M.; WRBAS, K. T.; SCHULTE-MÖNTING, J.; HELLWIG, E. Correlation of transversal microradiography and microhardness on in situ induced demineralization in irradiated and nonirradiated human dental enamel. Archives of Oral Biology, v. 44, n. 3, p. 243-251, 1999.

KNOTT, L.; BAILEY, A. J. Collagen cross-links in mineralizing tissues: a review of their chemistry, function, and clinical relevance. Bone, v. 22, n. 3, p. 181-187, 1998.

KOCHUEVA, M. V.; IGNATIEVA, N. Y.; ZAKHARKINA, O. L. Collagen structural changes in early radiation-induced damage. Sovremennye Tehnologii v Medicine, v. $4,2012$. 
KUGA, M. C.; FARIA, G.; SO, M. V.; KEINE, K. C.; SANTOS, A. D. D.; DUARTE, M. A. H.; KOPPER, P. M. P. The impact of the addition of iodoform on the physicochemical properties of an epoxy-based endodontic sealer. Journal of Applied Oral Science, v. 22, n. 2, p. 125-130, 2014.

LACERDA, C.; PLEIPIS, A. M. G.; GOISSIS, G. Hidrólise seletiva de carboxiamidas de resíduos de asparagina e glutamina em colágeno: preparação e caracterização de matrizes aniônicas para uso como biomateriais. Química Nova, v. 21, n. 3, p. 267-271, 1998.

LARSON, D. L.; LINDBERG, R. D.; LANE, E.; GOEPFERT, H. Major complications of radiotherapy in cancer of the oral cavity and oropharynx. A 10 year retrospective study. American Journal of Surgery, v. 146, n. 4, p. 531-536, 1983.

LEUNG, Y.; MORRIS, M. D. Characterization of the chemical interactions betwen 4MET and enamel by Raman spectroscopy. Dental Materials, v. 11, n. 3, p. 191-5, 1995.

LIANG, X.; ZHANG, J. Y.; CHENG, I. K.; LI, J. Y. Effect of high energy X-ray irradiation on the nano-mechanical properties of human enamel and dentine. Brazilian Oral Research, v. 30, 2016.

LIESHOUT, H. F. J.; BOTS, C. P. The effect of radiotherapy on dental hard tissue-a systematic review. Clinical Oral Investigations, v. 18, n. 1, p. 17-24, 2014.

LIU, Y.; HSU, C. Y. Laser-induced compositional changes on enamel: a FT-Raman study. Journal of Dentistry, v. 35, n. 3, p. 226-30, 2007.

LO, S. L.; YEN, Y. H.; LEE, P. J.; CHIH-HO LIU, C.; PU, C. M. Factors Influencing Postoperative Complications in Reconstructive Microsurgery for Head and Neck Cancer. Journal of Oral and Maxillofacial Surgery, 2016. In Press.

LOPES, F. C.; ROPERTO, R.; AKKUS, A.; AKKUS, O.; SOUZA-GABRIEL, A. E; SOUSA-NETO, M. D. Effects of different lasers on organic/inorganic ratio of radicular dentin. Lasers in Medical Science, p. 1-6, 2016. 
LOTHAIRE, P.; DE AZAMBUJA, E.; DEQUANTER, D.; LALAMI, Y.; SOTIRIOU, C.; ANDRY, G. \& AWADA, A. Molecular markers of head and neck squamous cell carcinoma: promising signs in need of prospective evaluation. Head \& Neck, v. 28, n. 3, p. 256-269, 2006.

MARTINS, C. V.; LEONI, G. B.; OLIVEIRA, H. F.; ARID, J.; QUEIROZ, A. M.; SILVA, L. A.; SOUSA-NETO, M. D. Influence of therapeutic cancer radiation on the bond strength of an epoxy or an MTA-based sealer to root dentine. International Endodontic Journal, v. 49, n. 11, p. 1065-1072, 2016.

MAVROPOUlos, E.; ROSSI, A. M.; COSTA, A. M.; PEREZ, C. A.; MOREIRA, J. C.; SALDANHA, M. Studies on the mechanisms of lead immobilization by hydroxyapatite. Environmental Science \& Technology, v. 1, n. 36, p. 1625-9, 2002.

MISHRA, H.; MISHRA, R.; SHAHI, U. P.; MANDAL, A. A Randomized Prospective Study of Concurrent Chemo-Radiotherapy vs Accelerated Hyperfractionation in Advanced Cancer of Head and Neck. Journal of Clinical and Diagnostic Research, v. 10, n. 10, p. XC15-XC18, 2016.

MJÖR, I. A. Dentin permeability: the basis for understanding pulp reactions and adhesive technology. Brazilian Dental Journal, v. 20, n. 1, p. 3-16, 2009.

MJÖR, I. A.; NORDAHL, I. The density and branching of dentinal tubules in human teeth. Archives of Oral Biology, v. 41, n. 5, p. 401-12, 1996.

MJÖR, I. A; FEJERSKOV, O. O Periodonto. Embriologia e Histologia Oral humana, 1991.

NANCI, A. Complexo Dentina-Polpa. Ten Cate Histologia Oral, ed. 7, p. 191-238, 2013.

NAVES, L. Z.; NOVAIS, V. R.; ARMSTRONG, S. R.; CORRER-SOBRINHO, L.; SOARES, C. J. Effect of gamma radiation on bonding to human enamel and dentin. Supportive Care in Cancer, v. 20, n. 11, p. 2873-2878, 2012. 
NESS-JENSEN, E.; GOTTLIEB-VEDI, E.; WAHLIN, K.; LAGERGREN, J. All-cause and cancer-specific mortality in GORD in a population-based cohort study (the HUNT study). Gut Journal, 2016. In Press.

NOVAIS, V. R.; SOARES, P. B.; GUIMARÃES, C. M.; SCHLIEBE, L. R.; BRAGA, S. S.; SOARES, C. J. Effect of Gamma Radiation and Endodontic Treatment on Mechanical Properties of Human and Bovine Root Dentin. Brazilian Dental Journal, v. 27 , n. 6 , p. 670-674, 2016.

NUTTING, C. M.; MORDEN, J. P.; HARRINGTON, K. J.; URBANO, T. G.; BHIDE, S. A.; CLARK, C.; ADAB, F. Parotid-sparing intensity modulated versus conventional radiotherapy in head and neck cancer (PARSPORT): a phase 3 multicentre randomised controlled trial. The Lancet Oncology, v. 12, n. 2, p. 127-136, 2011.

OHRN, K. E.; WAHLIN, Y. B.; SJÖDÉN, P. O. Oral status during radiotherapy and chemotherapy: a descriptive study of patient experiences and the occurrence of oral complications. Support Care Cancer, v. 9, n. 4, p. 247-57, 2001.

OLIVEIRA, M. M. H. S. Synthetic tooth enamel: SEM characterization of a fluoride hydroxyapatite coating for dentistry applications. Materials Research, v. 10, p. 115118, 2007.

OliveiRA, P. K.; TOSATO, M. G.; ALVES, R. D. S.; MARTIN, A. A.; FÁVERO, P. P.; RANIERO, L. Skin biochemical composition analysis by Raman spectroscopy. Revista Brasileira de Engenharia Biomédica, v. 28, n. 3, p. 278-287, 2012.

PASCON, F. M.; KANTOVITZ, K. R.; SOARES, L. E. S.; DO ESPÍRITO SANTO, A. M.; MARTIN, A. A.; PUPPIN-RONTANI, R. M. Morphological and chemical changes in dentin after using endodontic agents: Fourier transform Raman spectroscopy, energy-dispersive x-ray fluorescence spectrometry, and scanning electron microscopy study. Journal of Biomedical Optics, v. 17, n. 7, p. 0750081-0750086, 2012.

PASHLEY, D. H. Dentin predentin complex and its permeability: Physiologic overview. Journal of Dental Research, v. 64, p. 613-20, 1985. 
PIOCH, T.; GOLFELS, D.; STAEHLE, H. J. An experimental study of the stability of irradiated teeth in the region of the dentinoenamel junction. Dental Traumatology, $v$. 8, n. 6, p. 241-244, 1992.

PRESTES, R. C.; GOLUNSKI, S. M.; TONIAZZO, G.; KEMPKA, A. P.; DILUCCIO, M. Caracterização da fibra de colágeno, gelatina e colágeno hidrolisado. Revista Brasileira de Produtos Agroindustriais, v. 15, n. 4, p. 375-82, 2013.

QING, P.; HUANG, S.; GAO, S.; QIAN, L.; YU, H. Effect of gamma irradiation on the wear behaviour of human tooth enamel. Scientific Reports, v. 23, n. 5, p. 1-9, 2015.

RAUTIOLA, C. A.; CRAIG, R. G. The microhardness of cementum and underlying dentin of normal teeth and teeth exposed to periodontal diseases. Journal of Periodontology, v. 32, n. 4, p. 113-23, 1961.

REED, R.; XU, C.; LIU, Y.; GORSKI, J. P.; WANG, Y.; WALKER, M.P. Radiotherapy effect on nano-mechanical properties and chemical composition of enamel and dentine. Archives of Oral Biology, v. 60, n. 5, p. 690-7, 2015.

RODRIGUES, R. B. Efeitos da radioterapia nas propriedades biomecânicas e procedimentos adesivos à dentina humana. Uberlândia: Dissertação de Mestrado [Faculdade de Odontologia da Universidade Federal de Uberlândia], p. 78, 2015.

Rosales, A. C.; EsteVes, S. C.; JORGE, J.; AlMEIDA, O. P.; LOPES, M. A. Dental needs in Brazilian patients subjected to head and neck radiotherapy. Brazilian Dental Journal, v. 20, n. 1, p. 74-77, 2009.

ROŚ-MAZURCZYK, M.; WOJAKOWSKA, A.; MARCZAK, Ł.; POLAŃSKI, K.; PIETROWSKA, M.; JELONEK, K.; DOMIŃCZYK, I.; HAJDUK, A.; RUTKOWSKI, T.; SKŁADOWSKI, K.;WIDŁAK, $\mathrm{P}$. Ionizing radiation affects profile of serum metabolites: increased level of 3-hydroxybutyric acid in serum of cancer patients treated with radiotherapy. Acta Biochimica Polonica, 2016. In Press.

SALA, O. Introdução. Fundamentos da Espectroscopia Raman e no Infravermelho, ed. 2, p. 13-21, 1995. 
SANTIN, G. C.; PALMA-DIBB, R. G.; ROMANO, F. L.; DE OLIVEIRA, H. F.; NELSON FILHO, P.; DE QUEIROZ, A. M. Physical and adhesive properties of dental enamel after radiotherapy and bonding of metal and ceramic brackets. American Journal of Orthodontics and Dentofacial Orthopedics, v. 148, n. 2, p. 283-292, 2015.

SASAKI, K. M.; AOKI, A.; ICHINOSE, S.; ISHIKAWA, I. Morphological analysis of cementum and root dentin after Er:YAG laser irradiation. Lasers in Surgery and Medicine, v. 31, n. 2, p. 79-85, 2002.

SEIKALY, H.; JHA, N.; HARRIS, J. R.; BARNABY, P.; LIU, R.; WILLIAMS, D.; MCGAW, T.; RIEGER, J.; WOLFAARDT, J.; HANSON, J. Long-term outcomes of submandibular gland transfer for prevention of postradiation xerostomia. Archives of Otolaryngology - Head \& Neck Surgery, v. 130, n. 8, p. 956-61, 2004.

SHENOY, V. K.; SHENOY, K. K.; SHETTY, P. Management of oral health in patients irradiated for head and neck cancer: a review. Kathmandu University Medical Journal, v. 5, p. 117-120, 2007.

SILVA, A. R. S.; ALVES, F. A.; ANTUNES, M. F.; LOPES, G. M. A. Patterns of Demineralization and Dentin Reactions in Radiation-Related Caries. Caries Research, v. 43, p. 43-49, 2009.

SILVESTRIN, R. M.; ALENCASTRO, R. B. Identificação espectrométrica de compostos orgânicos. Livros Técnicos e Científicos, p. 429, 2007.

SOARES, C. J.; CASTRO, C. G.; NEIVA, N. A.; SOARES, P. V.; SANTOS-FILHO, P. C. F.; NAVES, L. Z.; PEREIRA, P. N. R. Effect of gamma irradiation on ultimate tensile strength of enamel and dentin. Journal of Dental Research, v. 89, n. 2, p. 159-164, 2010.

SOARES, C. J.; NEIVA, N. A.; SOARES, P. B. Effects of chlorhexidine and fluoride on irradiated enamel and dentin. Journal of Dental Research, v. 9, n. 5, p. 659-664, 2011. 
SOARES, L. E. S.; DO ESPIRITO SANTO, A. M.; BRUGNERA, A.; ZANIN, F. A. A.; MARTIN, A. A. Effects of Er: YAG laser irradiation and manipulation treatments on dentin components, part 2: energy-dispersive X-ray fluorescence spectrometry study. Journal of Biomedical Optics, v. 14, n. 2, p. 024002-024002-7, 2009.

SONJU CLASEN, A. B.; RUYTER, I. E. Quantitative determination of type A and type $B$ carbonate in human deciduous and permanent enamel by means of Fourier transform infrared spectrometry. Advances in Dental Research, v. 11, p. 523-527, 1997.

SØNSTEVOLD, T.; JOHANNESSEN, A. C.; STUHR, L. A rat model of radiation injury in the mandibular area. Radiation Oncology, v. 10, p. 129, 2015.

SPECHT, L. K.; KIRKEGAARD, J. Head and neck cancer. Ugeskr for Laeger, v. 164, n. 23, p. 3020-3023, 2002.

SPRINGER, I. N.; NIEHOFF, P.; WARNKE, P. H.; BÖCEK, G.; KOVÁCS, G.; SUHR, M. \& AÇIL, Y. Radiation caries-radiogenic destruction of dental collagen. Oral Oncology, v. 41, n. 7, p. 723-728, 2005.

STENSON, K. M.; POON, C. S. Overview of the diagnosis and staging of head and neck cancer. UpToDate Wolters Kluwer, 2016.

THIAGARAJAN, A.; IYER, N. G. Radiation-induced sarcomas of the head and neck. World Journal of Clinical Oncology, v. 5, n. 5, p. 973-981, 2014.

TOMITA, Y.; OSAKI, T. Gustatory impairment and salivary gland pathophysiology in relation to oral cancer treatment. International Journal of Oral and Maxillofacial Surgery, v. 19, n. 5, p. 299-304, 1990.

TORABINEJAD, M.; HANDYSIDES, R.; KHADEMI, A. A.; BAKLAND, L. K. Clinical implications of the smear layer in Endodontics: a review. Oral Surgery, Oral Medicine, Oral Pathology, Oral Radiology, and Endodontology, v. 94, n. 6, p. 658-66, 2002. 
TSUDA, H.; ARENDS, J. Raman spectroscopy in dental research: a short review of recent studies. Advances in Dental Research, v. 11, n. 4, p. 539-47, 1997.

VIEIRA, B.; HANS, E.W.; VAN, V. C.; VAN K. J.; VAN, H. W. Operations research for resource planning and -use in radiotherapy: a literature review. BMC Medical Informatics and Decision Making, v. 16, n. 1, p. 149, 2016.

VISSINK, A.; BURLAGE, F. R.; SPIJKERVET, F. K.; JANSMA, J.; COPPES, R. P. Prevention and treatment of the consequences of head and neck radiotherapy. Critical Reviews in Oral and Biology Medicine, v. 14, n. 3, p. 213-225, 2003.

WALKER, M. P.; WICHMAN, B.; CHENG, A.; COSTER, J.; WILLIAMS, K. B. Impact of radiotherapy dose on dentition breakdown in head and neck cancer patients. Practical Radiation Oncology, v. 1, p. 142-148, 2011.

WALTER, F.; FREISLEDERER, P.; BELKA, C.; HEINZ, C.; SÖHN, M.; ROEDER, F. Evaluation of daily patient positioning for radiotherapy with a commercial 3D surfaceimaging system (Catalyst ${ }^{\mathrm{TM}}$ ). Radiation Oncology, v. 11, n. 1, p.154, 2016.

YAP, L. F.; LAI, S. L.; PATMANATHAN, S. N.; GOKULAN, R.; ROBINSON, C. M.; WHITE, J. B.; CHAI, S. J.; RAJADURAI, P.; PREPAGERAN, N.; LIEW, Y. T.; LOPES, V.; WEI, W.; HOLLOWS, R. J.; MURRAY, P. G.; LAMBERT, D. W.; HUNTER, K. D.; PATERSON, I. C. HOPX functions as a tumour suppressor in head and neck cancer. Scientific Reports, v. 6, p. 38758, 2016. 



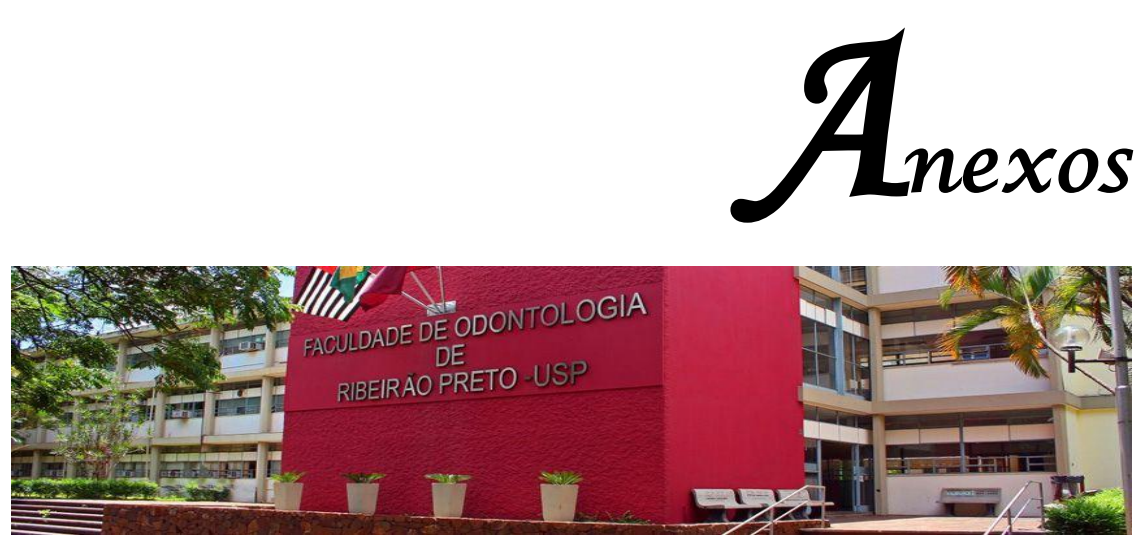



Anexo 1. Documento de aprovação do Comitê de Ética em Pesquisa

USP - FACULDADE DE
ODONTOLOGIA DE RIBEIRÃO
PRETO DA USP - FORP/USP

\section{PARECER CONSUBSTANCIADO DO CEP}

\section{DADOS DO PROJETO DE PESQUISA}

Título da Pesquisa: Efeito da irradiação gama na composição química da dentina.

Pesquisador: Lívia Bueno Campi

Área Temática:

Versão: 1

CAAE: 56735816.1 .0000 .5419

Instituição Proponente: Universidade de São Paulo

Patrocinador Principal: Financiamento Próprio

\section{DADOS DO PARECER}

Número do Parecer: 1.613 .009

\section{Apresentação do Projeto:}

A proposta do presente estudo é avaliar a composição química da dentina previamente submetida à radioterapia por meio da espectroscopia Raman e espectroscopia por energia dispersiva de raios-X. Vinte pré-molares inferiores humanos homólogos foram selecionados e distribuídos em 2 grupos $(n=10)$ de acordo com a irradiação: Grupo I - Não Irradiados; e Grupo II - Irradiados, submetidos à radioterapia fraccionada com raios-X de $6 \mathrm{MV}$. Os dentes serão seccionados e submetidos à análise da composição orgânica e inorgânica da superfície dentinária radicular por meio de microscópio Raman. As intensidades dos picos fosfato, carbonato e amidas I, II e III no espectro de Raman serão obtidas para determinar a quantidade de conteúdo mineral e colágeno.

\begin{tabular}{|c|c|c|c|}
\hline Endereço & : Avenida do Café s/no & & \\
\hline Bairro: & Monte Alegre & CEP: & $14.040-904$ \\
\hline UF: SP & Município: & RIBEIRAO PRETO & \\
\hline Telefone: & (16)3315-0493 & (16)3315-4102 & cep@forp.usp.br \\
\hline
\end{tabular}




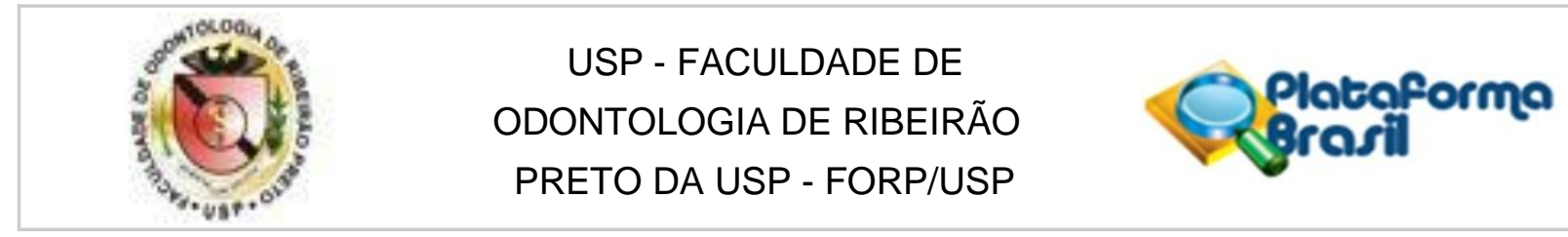

Continuação do Parecer: 1.613.009

\section{Objetivo da Pesquisa:}

A proposta do presente estudo consiste em analisar a composição química da dentina submetida à radioterapia por raios-X de $6 \mathrm{MV}$ em regime fracionado (2 Gy, por 5 dias consecutivos, com 30 ciclos, durante 6 semanas, perfazendo 60 Gy) por meio da espectroscopia Raman.

\section{Avaliação dos Riscos e Benefícios:}

Projeto in vitro - dentes doados pelo Biobanco da FORP/USP

\section{Comentários e Considerações sobre a Pesquisa:}

Pesquisa original, relevante, bem embasada cientificamente.

Considerações sobre os Termos de apresentação obrigatória:

Adequados.

\section{Recomendações:}

Aprovado.

Conclusões ou Pendências e Lista de Inadequações:

Aprovado.

\section{Considerações Finais a critério do CEP:}

Conforme deliberado na 197ª Reunião CEP/FORP/USP, realizada em 29/06/2016.

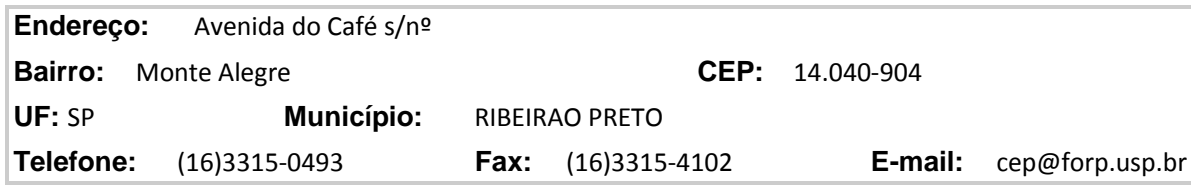




\section{USP - FACULDADE DE ODONTOLOGIA DE RIBEIRÃO PRETO DA USP - FORP/USP}

Continuação do Parecer: 1.613.009

Este parecer foi elaborado baseado nos documentos abaixo relacionados:

\begin{tabular}{|c|c|c|c|c|}
\hline Tipo Documento & Arquivo & Postagem & Autor & Situação \\
\hline $\begin{array}{l}\text { Informações Básicas } \\
\text { do Projeto }\end{array}$ & $\begin{array}{c}\text { PB_INFORMAÇÕES_BÁSICAS_DO_P } \\
\text { ROJETO_713034.pdf }\end{array}$ & $\begin{array}{c}06 / 06 / 2016 \\
11: 14: 18\end{array}$ & Lívia Bueno Campi & Aceito \\
\hline $\begin{array}{c}\text { Projeto Detalhado / } \\
\text { Brochura } \\
\text { Investigador }\end{array}$ & projeto.docx & $\begin{array}{c}06 / 06 / 2016 \\
11: 14: 01\end{array}$ & Lívia Bueno Campi & Aceito \\
\hline Outros & compromissodecitacao.pdf & $\begin{array}{c}30 / 05 / 2016 \\
15: 34: 58\end{array}$ & Lívia Bueno Campi & Aceito \\
\hline $\begin{array}{c}\text { Declaração de } \\
\text { Manuseio Material } \\
\text { Biológico / } \\
\text { Biorepositório / } \\
\text { Biobanco }\end{array}$ & declaracaoaoCEP.pdf & $\begin{array}{c}30 / 05 / 2016 \\
15: 33: 53\end{array}$ & Lívia Bueno Campi & Aceito \\
\hline $\begin{array}{c}\text { Biorepositório / } \\
\text { Biobanco }\end{array}$ & declaracaoaoCEP.pdf & $\begin{array}{c}30 / 05 / 2016 \\
15: 33: 53\end{array}$ & Lívia Bueno Campi & Aceito \\
\hline Folha de Rosto & folhaderosto.pdf & $\begin{array}{l}30 / 05 / 2016 \\
15: 32: 25\end{array}$ & Lívia Bueno Campi & Aceito \\
\hline $\begin{array}{l}\text { Declaração de } \\
\text { Instituição e } \\
\text { Infraestrutura }\end{array}$ & Autorizacao_infra.pdf & $\begin{array}{c}19 / 05 / 2016 \\
22: 01: 17\end{array}$ & Lívia Bueno Campi & Aceito \\
\hline $\begin{array}{c}\text { TCLE / Termos de } \\
\text { Assentimento / } \\
\text { Justificativa de } \\
\text { Ausência }\end{array}$ & justificativa_ausencia.pdf & $\begin{array}{c}19 / 05 / 2016 \\
22: 00: 43\end{array}$ & Lívia Bueno Campi & Aceito \\
\hline
\end{tabular}

\section{Situação do Parecer:}

Aprovado

\section{Necessita Apreciação da CONEP:}

Não

RIBEIRAO PRETO, 29 de Junho de 2016.

\section{Assinado por: \\ Simone Cecilio Hallak Regalo \\ (Coordenador)}

Endereço: Avenida do Café s/no

Bairro: Monte Alegre

UF: SP

Telefone:
Município:

(16)3315-0493

RIBEIRAO PRETO

Fax: (16)3315-4102

E-mail: cep@forp.usp.br 